\title{
AXIAL BEHAVIOR OF HIGH-STRENGTH CONCRETE-FILLEDHIGH-STRENGTH SQUARE STEEL TUBULAR STUB COLUMNS
}

\author{
Guo-Chang $\mathrm{Li}^{1}$, Bo-Wen Chen ${ }^{1}$, Zhi-Jian Yang ${ }^{1,}{ }^{*}, \mathrm{Han}-\mathrm{bin}$ Ge ${ }^{2}$ and Xiao Li ${ }^{1}$ \\ ${ }^{1}$ School of Civil Engineering, Shenyang Jianzhu University, Shenyang, China \\ ${ }^{2}$ Department of Civil Engineering, Meijo University, Nagoya, Japan \\ *(Corresponding author: E-mail: faemail@163.com)
}

\section{A B S T RA C T}

To investigate the fundamental behavior of concrete-filled steel tubes (CFSTs) consisting of high-strength materials, this study experimentally explored the axial performance of eight high-strength concrete-filled high-strength square steel tube (HCFHSST) stub columns considering various yield strengths of steel ( $f_{\mathrm{y}}$ from $566.90 \mathrm{MPa}$ to $\left.889.87 \mathrm{MPa}\right)$. Thereafter, the compatibility between the strengths of steel and concrete was discussed. Simulations were also performed to evaluate the structural responses of the column, incorporating the crushing failure and load-carrying performance of concrete, the local and post-local buckling behaviors of the column, and the steel tubular confinement effect.Based on existing literatures, a test database including data on 170 CFST stub columns with high-strength materials was established. The calculations from various design codes were compared with the peak-loads of these 170 samples, which identified that Eurocode 4 afforded the closest predictions on average, while it was unsafe for columns incorporating conventional-strength steel and high-strength concrete. As for columns with compact sections, AISC 360 can be safely utilized for predicting the peak-loads.

\section{ARTICLE HISTORY}

\begin{tabular}{|c|c|}
\hline Received: & 29 April 2020 \\
\hline Revised: & ecember 2020 \\
\hline Accepted: & 12 December 2020 \\
\hline
\end{tabular}

\section{KE Y W O R D S}

Concrete-filled steel tube (CFST); High-strength material; Failure mechanism; Composite action

\section{Introduction}

Concrete-filled steel tubes (CFSTs) are extensively adopted in engineering applications owing to the beneficial composite action. Through the use of high-strength materials for CFST columns, an innovative structural member can be produced. This helps to achieve better mechanical behavior and reduce the cross-section of the column, which can improve building space usage. Using the current technology, the production of high-strength materials has become possible [1], and the use of these materials is promising as they afford significant advantages [2]. However, current design codes, such as Eurocode 4 [3], AISC 360 [4], and GB 50936 [5], set several limitations on the application of high-strength steel tube and concrete, as reported by several previous studies [6-8]. Given this background, further explorations regarding the fundamental behavior of CFSTs and database enrichment remain necessary.

Thai et al. [9] collected 3103 test samples, including stub and long CFSTs subjected to axial and eccentric loads. Then, a comprehensive database of circular, square, and rectangular CFSTs was established; the material strengths, namely $f_{\mathrm{y}}$ and $f_{\mathrm{c}}^{\prime}$, were $115.0 \mathrm{MPa}$ to $853.0 \mathrm{MPa}$ and 7.6 $\mathrm{MPa}$ to $186.0 \mathrm{MPa}$, respectively. According to Ref. [9], among existing tests,only $13.6 \%$ and $12.5 \%$ of the tested specimens adopted high-strength steel (HSS) with $f_{\mathrm{y}}>460 \mathrm{MPa}$ and high-strength concrete (HSC) with $f_{\mathrm{c}}^{\prime}>90 \mathrm{MPa}$, respectively; moreover, the highest $f_{\mathrm{y}}$ value employed for the CFST test specimens with square or rectangular cross-sections was $835 \mathrm{MPa}$. In existing literatures, only a few reports focus on the axial behavior of CFSTs with HSS whose $f_{\mathrm{y}}$ reached 800 $\mathrm{MPa}$.

Yan et al. [10] performed experimental investigations on 32 stub columns with HSS and high-performance concrete under axial compression, where $f_{\mathrm{y}}$ and $f_{\text {cu-100 }}$ (obtained from tests on 100-mm-wide cubic blocks) were from 444.6 $\mathrm{MPa}$ to $668.8 \mathrm{MPa}$ and 102.4 MPa to $141.0 \mathrm{MPa}$, respectively. It was observed that the ductility of such columns increased with the confinement coefficient. Lee et al. [11] experimentally investigated the axial response of five rectangular CFSTs made of high-strength materials, where $f_{\mathrm{y}}$ and $f_{\mathrm{c}}^{\prime}$ were from $301 \mathrm{MPa}$ to $746 \mathrm{MPa}$ and $70.5 \mathrm{MPa}$ to $83.6 \mathrm{MPa}$, respectively. Furthermore, it was numerically demonstrated that the peak-loads sustained by steel tube and concrete components were mainly influenced by the material strength and width-to-wall-thickness ratio. This finding was also reported by Lai and Varma [12].

Lam and Williams [13] experimentally confirmed that the steel-concrete bonding strength was critical to the axial behavior of stub columns filled with 100-MPa-HSC.Guler et al. [14] experimentally observed that high-strength CFST stub columns with circular sections exhibited greater steel-concrete bonding strengths than those with square sections. Additionally, new concrete constitutive models that considered the confinement effect were recommended by Aslani et al. [15] and Liang et al. [16] through investigations on the behaviors of axially loaded CFSTs made of high-strength materials.
Patel et al. [17] numerically confirmed that AISC 360 [4] was conservative in estimating the peak-loads of circular cases employing ultra-high-strength concrete $\left(f_{\mathrm{c}}^{\prime}\right.$ up to $\left.193.3 \mathrm{MPa}\right)$. In contrast, GB 50936 [5] was demonstrated to be unconservative [17]. Wei et al. [18] tested 20 circular CFST stub columns with $f_{\mathrm{y}}$ up to $1153 \mathrm{MPa}$ and $f_{\mathrm{c}}^{\prime}$ up to $125 \mathrm{MPa}$, and found that the calculations of AIJ [19] were close to the test results.For square or rectangular columns using high-strength materials, Aslani et al. [15] and Kang et al. [20] found that AS 5100 [21] offered a satisfactory prediction. Lai et al. [22] reported that Eurocode 4 [3] could be conservatively adopted to predict the peak-loads of CFST stub columns with $f_{\mathrm{y}}$ up to $780 \mathrm{MPa}$ and $f_{\mathrm{c}}^{\prime}$ from $150 \mathrm{MPa}$ to $190 \mathrm{MPa}$.

Based on foregoing research on the axial behavior of CFSTs fabricated using high-strength materials, numerous studies have been performed to explore the ductility, load sustained by each component, steel-concrete bonding behavior, and confined concrete model in CFSTs. Moreover, the peak-loads of CFSTs were predicted by using current design codes. These previous investigations have provided significant contributions toward the engineering applications of CFSTs.

Thus far, studies on the failure mechanism of CFSTs are limited. It should be noted that the typical failure mode of an axially loaded high-strength CFST stub column is characterized by bulging near the ends or at the middle of the steel tube, along with concrete crushing. This finding was also observed in many available tests $[8,11,23,24]$. However, investigations on the crushing mechanism of HSC are rare.Simultaneously, although the confinement action in composite columns has been analyzed using various methods [25-27],studies on the contact stress variation along the height of the high-strength CFST stub column are limited.Moreover, the variation of the longitudinal stress in the concrete elements along the column height can also be adopted to reflect the steel tubular constraint action, while therelated investigations remain unclear. Hence, further studies are necessary.

To address these research gaps, this work mainly focuses on factors such as (a) steel-concrete strength compatibility, (b) crushing failure of concrete, (c) local and post-local buckling behaviors, (d) steel tubular confinement, and (e) applicability of the current design codes. A more detailed outline is presented as follows.

In this study, tests were performed on eight concentrically compressed high-strength concrete-filled high-strength square steel tubular (HCFHSST) stub columns with $f_{\mathrm{y}}$ from $566.90 \mathrm{MPa}$ to $889.87 \mathrm{MPa}$. Numerical studies were also conducted to further analyze the failure mechanism of HCFHSST columns and the steel-concrete composite action. Moreover, a test database including data on 170 high-strength CFST samples was established. The feasibilities of utilizing current design codes to predict the peak-loads of axially compressed CFST stub columns incorporating high-strength materialswere alsodiscussed.The results of this research are anticipated to provide useful insights for engineering practices. 


\section{Experimental study}

\subsection{Design of specimens}

In the experiments, eight HCFHSST stub columns were subjected to axial compression using a $10000 \mathrm{kN}$ testing machine. The column parameters are summarized in Table 1 . The sectional dimension of each specimen was 150 $\mathrm{mm} \times 150 \mathrm{~mm}$, and column height was $450 \mathrm{~mm}$. Seamless square steel tubes with $f_{\mathrm{y}}$ from $566.90 \mathrm{MPa}$ to $889.87 \mathrm{MPa}$ (actual measured values) and HSC provided by a commercial concrete corporationwere employed.Mixture proportions of the concrete are tabulated in Table 2. Before the HCFHSST column tests, the cubic concrete blocks (width of $150 \mathrm{~mm}$ ) were tested under axial loading, and the average strength was $90 \mathrm{MPa}$

Table 1

Parameters and test results of specimens

\begin{tabular}{|c|c|c|c|c|c|c|c|c|c|}
\hline No. & $B(\mathrm{~mm})$ & $t(\mathrm{~mm})$ & $L(\mathrm{~mm})$ & $L / B$ & $f_{\mathrm{y}}(\mathrm{MPa})$ & $f_{\mathrm{u}}(\mathrm{MPa})$ & $f_{\text {cu }}(\mathrm{MPa})$ & $P_{\mathrm{u}}(\mathrm{kN})$ & $\Delta_{\mathrm{u}}(\mathrm{mm})$ \\
\hline HSSA1-1 & 150 & 5 & 450 & 3 & 566.90 & 644.00 & 90 & 3510.5 & 1.66 \\
\hline HSSA $1-2$ & 150 & 5 & 450 & 3 & 566.90 & 644.00 & 90 & 3363.5 & 1.50 \\
\hline HSSA2-1 & 150 & 5 & 450 & 3 & 780.75 & 830.19 & 90 & 4006.5 & 1.78 \\
\hline HSSA2-2 & 150 & 5 & 450 & 3 & 780.75 & 830.19 & 90 & 3975.0 & 2.26 \\
\hline HSSA3-1 & 150 & 5 & 450 & 3 & 838.00 & 880.00 & 90 & 4124.5 & 1.98 \\
\hline HSSA3-2 & 150 & 5 & 450 & 3 & 838.00 & 880.00 & 90 & 4197.5 & 1.86 \\
\hline HSSA4-1 & 150 & 5 & 450 & 3 & 889.87 & 947.09 & 90 & 4257.5 & 2.12 \\
\hline HSSA4-2 & 150 & 5 & 450 & 3 & 889.87 & 947.09 & 90 & 4248.5 & 1.79 \\
\hline
\end{tabular}

Note: In HSSA1-2, HSSA denotes the high-strength square CFST specimen under axial compression; 1 and 2 indicate the first group of specimens and the identical specimen, respectively; $B$ and $L$ are the cross-sectional outer width and column length, respectively; $t$ is the steel tubular wall-thickness; $f_{\mathrm{y}}$ and $f_{\mathrm{u}}$ are the measured steel yield and ultimate tensile strengths, respectively; $f_{\mathrm{cu}}$ is the measured concrete strength using 150 -mm cubic blocks; $P_{\mathrm{u}}$ is the measured peak-load; $\Delta_{\mathrm{u}}$ is the corresponding longitudinal deformation.

Table 2

Mixture proportions of high-strength concrete (unit: $\mathrm{kg} / \mathrm{m}^{3}$ )

\begin{tabular}{cccccc}
\hline Mixture & Cement & Admixture & Sand & Coarse aggregate & Superplasticizer \\
\hline Proportion & 500 & 100 & 660 & 1150 & 130 \\
\hline
\end{tabular}

\subsection{Data acquisition}

As shown in Fig. 1, flat plate loading was adopted in the tests, and the axial deformation values of the specimens were measured using displacement transducers (i.e., LVDTs) located on both sides of the specimens. Longitudinal and transverse strain gauges were attached to the midpoints of surfaces 1-4 (S1-S4). All test data were collected by the IMP automatic acquisition system. The applied load in each loading stage was $11_{10}-1 / 15$ of the predicted ultimate load, and each stage lasted for approximately 3 to 4 min. When the specimen load approximately approached the ultimate load, gradual and continuous loading was implemented. The loading rate during the post-peak stage was around $1.5 \mathrm{~mm} / \mathrm{min}$.

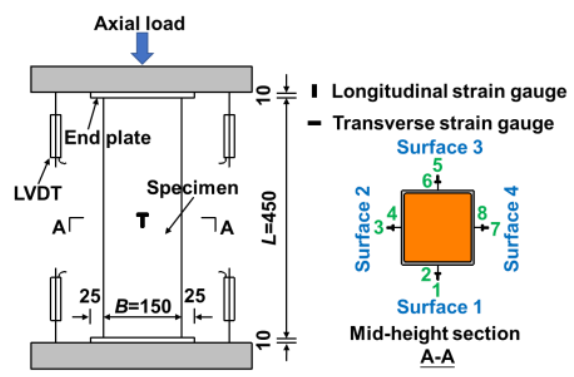

Fig. 1 Test set-up

\subsection{Failure modeand process}

The failure modes of the HCFHSST columns under axial compression are presented in Fig. 2. Outward buckling deformations were observed at the ends and mid-heights of the steel tubes. As illustrated in Fig. 2(b), when the steel tubes of the specimens were removed, the concrete was visibly crushed, particularly at the positions where the steel tubes bulged.

As presented in Fig. 3, the HSSA1-2 specimen was employed as an example to further illustrate the failure process of the columns. At the peak-load, outward buckling deformations initially occurred at the top end of the column and the bulges were insignificant. During the descending stage of loading, as the applied load reduced to $-75 \% P_{\mathrm{u}}$ (“--" indicates post-peak stage), bulges were distinctly observed at the mid-height section. Simultaneously, the outward deformation that appeared near the column end gradually increased at this stage. Further explanations of the failure process based on numerical investigations are provided in Section 3.

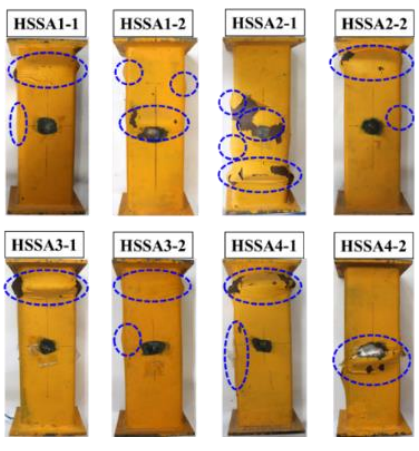

(a) Failure modes of specimens

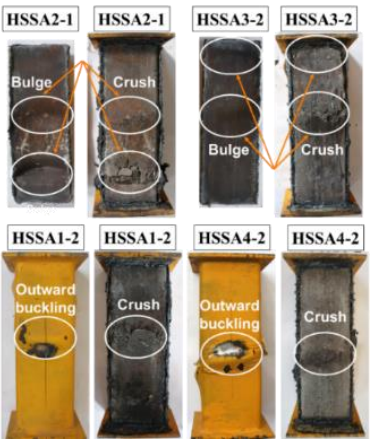

(b) Failure patterns in concrete
Fig. 2 Failure modes of HCFHSST columns

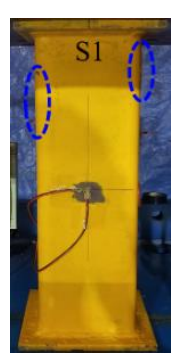

(a) Peak-load

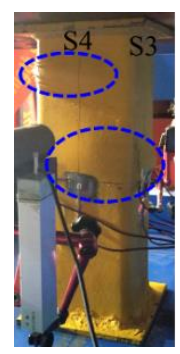

(b) $-75 \% P_{\mathrm{u}}$
Fig. 3 Failure process of HSSA1-2 specimen

\subsection{Load-longitudinal displacement curves}

As presented in Fig. 4, the change trends of the load-displacement curves for HSSA1-2, HSSA2-1, and HSSA2-2 specimens were similar. Among these, the HSSA1-2 was used to describe the loading process of HCFHSST specimens.During the pre-peak loading phase of HSSA1-2, the stiffness of the load-displacement curve was high, and the nonlinear trend was not visibly observed in this curve.During the post-peak loading stage, the load abruptly decreased from $3304.5 \mathrm{kN}$ to $2532.0 \mathrm{kN}$ (a $23.4 \%$ reduction) with increasing the longitudinal displacement, because the brittle failure of concrete occurred 
during the test. This phenomenon of "sudden descent" (Fig. 4) was also observed in Refs. [8, 28]. Meanwhile, the longitudinal displacement increased from 1.63 to $1.78 \mathrm{~mm}$ (i.e., $9.2 \%$ ). Thereafter, the load slightly declined from $2532.0 \mathrm{kN}$ to $2525.0 \mathrm{kN}$ (i.e., $0.3 \%$ ), whereas the longitudinal displacement evidently increased from $1.78 \mathrm{~mm}$ to $2.37 \mathrm{~mm}$ (i.e., $33.1 \%$ ).

Overall, the loads of the HSSA1-2, HSSA2-1, and HSSA2-2 specimens abruptly declined at $-98.2 \% P_{\mathrm{u}}--99.7 \% P_{\mathrm{u}}$. However, the load of the HSSA3-2 specimen started to decrease rapidly at a lower load level $\left(-91.9 \% P_{\mathrm{u}}\right)$, and the load reduction was relatively small. In addition, this phenomenon was not observed in the HSSA4-1 and HSSA4-2 specimens because the steel tubular confinement effect increased with $f_{\mathrm{y}}$. Hence, HSS with $f_{\mathrm{y}}=838.00 \mathrm{MPa}$ and 889.87 $\mathrm{MPa}$ could provide sufficient restraints to delay and prevent the concrete from significant split after reaching the peak-loads, ensuring that the axially loaded stub columns had adequate residual mechanical behaviors. Another reason is that the concrete in the column with a lower $f_{\mathrm{y}}$ value sustained more axial load.

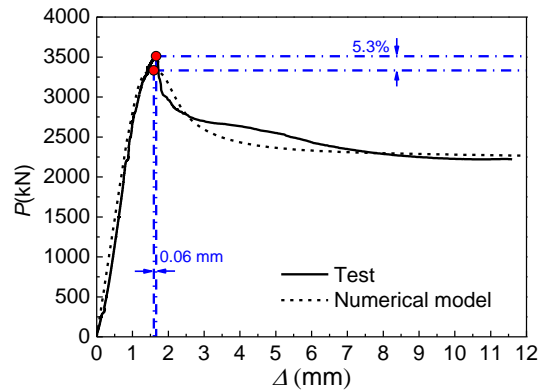

(a) HSSA1-1

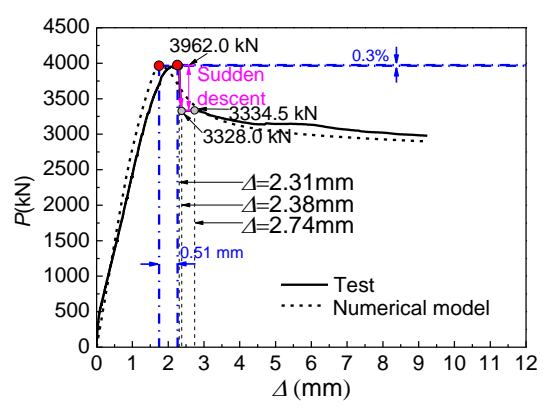

(d) HSSA2-2

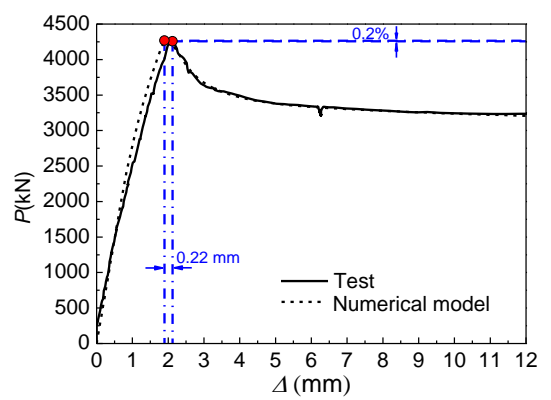

(g) HSSA4-1

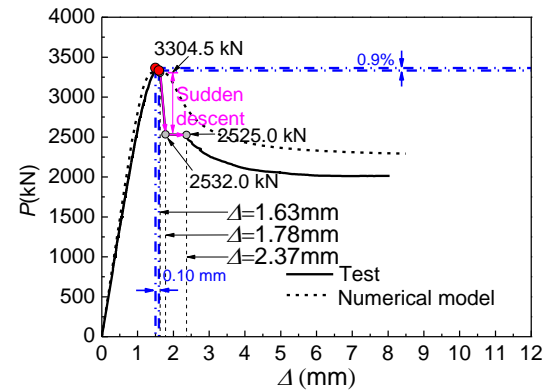

(b) HSSA1-2

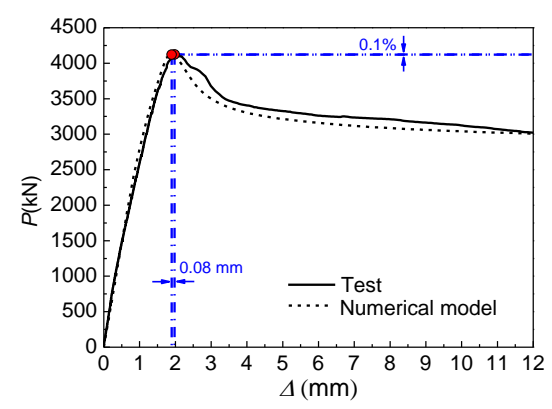

(e) HSSA3-1

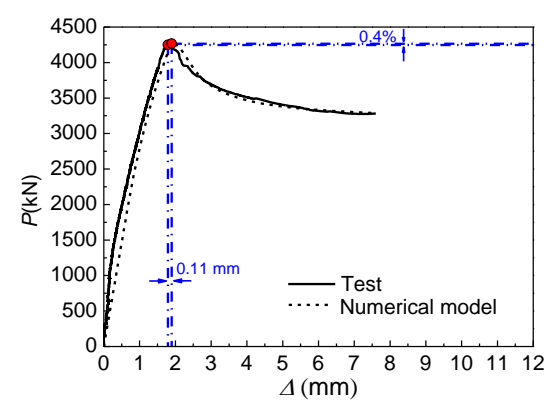

(h) HSSA4-2

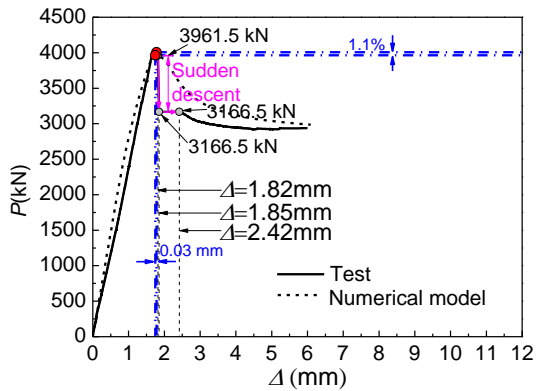

(c) HSSA2-1

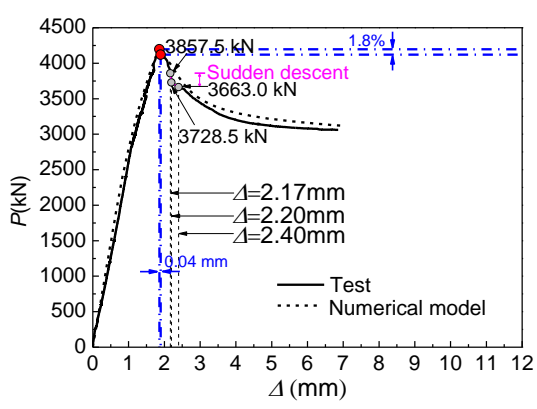

(f) HSSA3-2

Fig. 4 Comparative results of load-longitudinal displacement curves

\subsection{Strain and stress variations}

As expected, outward buckling was observed in the HCFHSST specimens. This occurred at $1 / 2 L$ of the HSSA4- 2 specimen, in which the HSS of $f_{\mathrm{y}}=889.87$ MPa effectively prevented the brittle failure mode. Accordingly, as illustrated in Fig. 5, eight strain gauge (SG) values in the HSSA4-2 specimen are obtained to determine the strain variation trend, and the locations of "1-8" and four surfaces of "S1-S4" are indicated in Fig. 1.

Based on Fig. 5, the SG1, SG3, and SG7 values were similar during the initial loading period, and the strain values increased with the axial load. After the load approximately achieved $2500 \mathrm{kN}\left(58.8 \% P_{\mathrm{u}}\right)$, the increase in the SG7 value was smaller than that in the SG1 value. Compared with other transverse strain values, the enhancement in the SG8 value was more pronounced. The abovementioned analysis demonstrated that the deformation at $1 / 2 L$ of S4 mainly concentrated in the transverse direction, and the extent of outward buckling was also evident. After the load approximately reached $3500 \mathrm{kN}(82.4 \%$ $P_{\mathrm{u}}$ ), strain reversal gradually occurred because of local buckling. Moreover, two bulges were observed in S3 of the steel tube. It was found that before the peak-load, the SG5 value increased greater than other longitudinal strain values, and the development trends of the SG2, SG4, and SG6 values were similar. This indicated that the deformation at ${ }^{1} / 2 L$ of S3 mainly concentrated in the longitudinal direction, and the degree of outward buckling was relatively small.

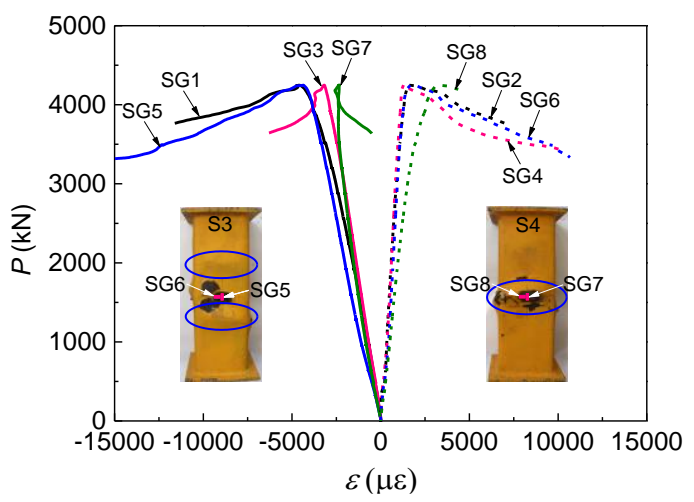

Fig. 5 Load-strain curves

The transverse stress $\left(\sigma_{\mathrm{h}}\right)$, longitudinal stress $\left(\sigma_{\mathrm{v}}\right)$, and equivalent stress $\left(\sigma_{\mathrm{z}}\right)$ variations at the mid-height of S1 in the HSSA4-2 column are exerted as an example to present the stress developments, asplotted in Fig. 6. Other specimens exhibit similar trends. The stresses were computed according to the SG1 and SG2 values, and the detailed assumption and computations can be found in Refs. [29,30]. The calculated stresses are sensitive to the strain variations. As depicted in Fig. 6 , in the initial loading process, $\sigma_{\mathrm{h}}$ apparently 
increased, owing to the temporary and minor fluctuations in the transverse strain. In general, $\sigma_{\mathrm{h}}$ was considerably lower than $\sigma_{\mathrm{v}}$ and $\sigma_{\mathrm{z}}$ during the entire loading process and mainly enhanced after $P_{\mathrm{u}}$. The steel tube practically yielded when the peak-load was attained. After yielding, both $\sigma_{\mathrm{v}}$ and $\sigma_{\mathrm{z}}$ gradually reduced although the steel underwent the strain hardening stage.

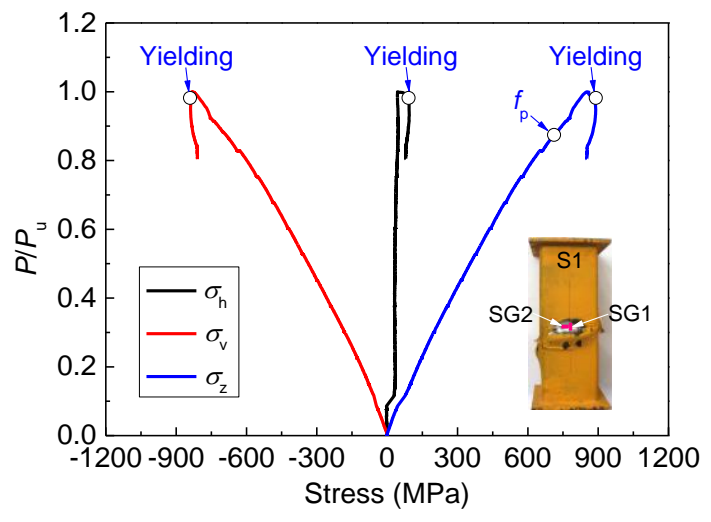

Fig. 6 Stress variations

\section{Numerical study}

\subsection{Modeling}

ABAQUS was adopted for the numerical simulation of HCFHSST columns under axial compressive loads. The C3D8R element was selected to model each part, as described in Fig. 7. The end-plates completely transferred the axial load to the columns. Accordingly, these plates were assumed to be rigid in the modeling process based on a previous study of the authors [31]. The end-plates were attached to the ends of the columns, and the "Tie" option in ABAQUS was selected to simulate the connections between two end-plates and a steel tube. The interaction between concrete and an end-plate was set as "Hard contact". Moreover, the "hard contact" and "friction contact" were defined between a steel tube and concrete, and a friction coefficient of 0.6 was used in this study.

The boundary conditions of the model are depicted in Fig. 7. The displacement in z-direction at the top of the column was released, whereas the remaining displacement and rotation at the top and bottom of the model were constrained. This method was also suggested by Patel et al. [17]. Additionally, the mesh size of $B / 15$ was selected for the concrete and steel tube in the current study based on the proposal of Taoet al. [32].

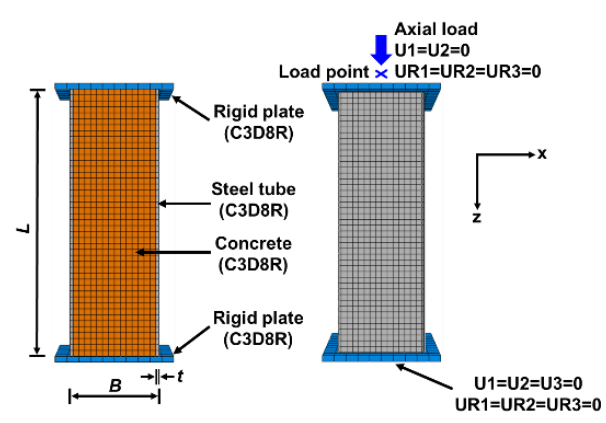

Fig. 7 Finite element modeling

\subsection{Constitutive model}

The bi-linear constitutive model was utilized for simulating the property of the HSS, as expressed in Eq. (1), where the elastic modulus $\left(E_{\mathrm{s}}\right)$ and Poisson's ratio wereset as $206 \mathrm{GPa}$ [5] and 0.3 [32], respectively. Furthermore, in the parametric studies, $f_{\mathrm{u}}$ was computed according to Eqs. (2) [32] and (3) [33] for steels with $f_{\mathrm{y}} \leq 800 \mathrm{MPa}$ and $f_{\mathrm{y}}>800 \mathrm{MPa}$, respectively.

$$
\sigma= \begin{cases}E_{\mathrm{s}} \cdot \varepsilon & \left(\sigma \leq f_{\mathrm{y}}\right) \\ f_{\mathrm{y}}+0.01 E_{\mathrm{s}}\left(\varepsilon-\varepsilon_{\mathrm{y}}\right) & \left(\sigma>f_{\mathrm{y}}\right)\end{cases}
$$

$f_{\mathrm{u}}= \begin{cases}{\left[1.6-2 \times 10^{-3}\left(f_{\mathrm{y}}-200\right)\right] f_{\mathrm{y}}} & \left(200 \mathrm{MPa} \leq f_{\mathrm{y}} \leq 400 \mathrm{MPa}\right) \\ {\left[1.2-3.75 \times 10^{-4}\left(f_{\mathrm{y}}-400\right)\right] f_{\mathrm{y}}} & \left(400 \mathrm{MPa} \leq f_{\mathrm{y}} \leq 800 \mathrm{MPa}\right)\end{cases}$ $f_{\mathrm{u}}=0.96 f_{\mathrm{y}}+\frac{650}{f_{\mathrm{y}}^{0.3}} \quad\left(f_{\mathrm{y}}>800 \mathrm{MPa}\right)$

The constitutive equations of confined concrete proposed by Han et al. [34] were chosen to describe the compressive property of HSC, which are feasible for $f_{\text {cu }}$ values in the range of $30 \mathrm{MPa}-120 \mathrm{MPa}$, and the specific expressions are provided in Eq. (4).Furthermore, the Elastic modulus was determined as $E_{\mathrm{c}}=3320\left(f_{\mathrm{c}}^{\prime}\right)^{1 / 2}+6900(\mathrm{MPa})$ [35] and Poisson's ratio was set as 0.2 [36]. The dilation angle and other parameters were consistent with those determined in a previous study of the authors [31].

$y= \begin{cases}2 x-x^{2} & (x \leq 1) \\ \frac{x}{\beta_{0}(x-1)^{\eta}+x} & (x>1)\end{cases}$

where $\quad x=\varepsilon \quad \varepsilon_{0}, \quad \mathrm{y}=\sigma / f_{\mathrm{c}}^{\prime}, \varepsilon_{\mathrm{c}}=\left(1300+12.5 f_{\mathrm{c}}^{\prime}\right) \times 10^{-6}, \quad \varepsilon_{0}=\varepsilon_{\mathrm{c}}+800 \xi^{0.2} \times 10^{-6}$, $\beta_{0}=\left(f_{\mathrm{c}}^{\prime}\right)^{0.1} /\left(1.2(1+\xi)^{1 / 2}\right)$, and $\eta=1.6+1.5 / x$. The confinement coefficient is computed as $\xi=f_{\mathrm{y}} A_{\mathrm{s}} /\left(f_{\mathrm{ck}} A_{\mathrm{c}}\right) ; f_{\mathrm{ck}}$ is the prismatic concrete characteristic strength; $A$ is the cross-sectional area of the component; and subscripts "s and c" represent steel and concrete, respectively.

In addition, the tensile properties of concrete were calculated using the GFI energy method illustrated in Refs. [31,37], and the specific expressions are as follows:

$G_{\mathrm{f}}=a \cdot\left(f_{\mathrm{c}}^{\prime} / 10\right)^{0.7} \times 10^{-3} \quad(\mathrm{~N} / \mathrm{mm})$

where $a=1.25 d_{\max }+10, d_{\max }$ denotes the maximum coarse aggregate size, and $f_{\mathrm{c}}^{\prime}$ is the cylindrical concrete strength. Additionally, the concrete cracking stress can be computed as $\sigma_{\mathrm{t} 0}=0.26 \times\left(1.25 f_{\mathrm{c}}^{\prime}\right)^{2 / 3}$. The strength conversion relationship of $f_{\mathrm{cu}}, f_{\mathrm{c}}^{\prime}$, and $f_{\mathrm{ck}}$ in the current study was determined according to Ref. [31].

\subsection{Validation of numerical model}

The simulation results were compared against the test results, as plotted in Fig. 4, where the blue lines illustrate their differences. The figure indicates that the load-longitudinal displacement curves predicted by the numerical studies exhibit satisfactory agreement with the test results, confirming the accuracy of the finite element models. It should be noted that, for the HSSA1-2, HSSA2-1, and HSSA2-2 specimens (Fig. 4), the applied load suddenly reduced and the corresponding longitudinal deformation rapidly enhanced after achieving the peak-loads. Therefore, for these specimens, some deviations exist in the post-peak stages of the load-longitudinal deformation curves, which is a reasonable phenomenon.

\subsection{Load-longitudinal displacement curve analysis}

A numerical model that matched the HSSA1-1 (as well as HSSA1-2) experimental specimen was extracted as a representative model to further analyze the axial behavior of HCFHSST columns. The load-longitudinal displacement curve of this model and the definitions of several events are shown in Fig. 8. The initial stiffness of the load-longitudinal displacement curve was relatively large during the elastic stage (OA stage). As the load reached $84.2 \%$ and $98.5 \%$ of the peak-load, the steel tubular stress at the column mid-height reached the proportional limit and yield strength of steel, respectively. The HCFHSST column gradually developed plasticity after event A, and a minor nonlinear development trend was observed in the load-longitudinal displacement curve. The sufficient plasticity development could be found in the HCFHSST column after event B. With increasing the longitudinal displacement, the load slowly increased, and the yielding load was found to considerably approximate the peak-load of the HCFHSST stub column.

At event $\mathrm{C}\left(P=99.6 \% P_{\mathrm{F}}\right)$, the ultimate compressive strain was achieved for concrete along the longitudinal direction. At event $\mathrm{D}$, the peak-load of the column was reached, and the longitudinal displacement was $1.60 \mathrm{~mm}$, which increased by $23.1 \%$ compared with that at event B. After event D, due to the yielding of steel tube and the crushing of concrete, the load began to decrease as longitudinal deformation increased. After event $\mathrm{F}\left(P=-70 \% P_{\mathrm{F}}\right)$, the load bearing capacity of the model tended to be stable with an increase in deformation. This indicates that the HCFHSST columns have satisfactory residual mechanical behaviors, that is, the load bearing capacity can still reach approximately $70 \%$ of the peak-load before unloading (event G). 


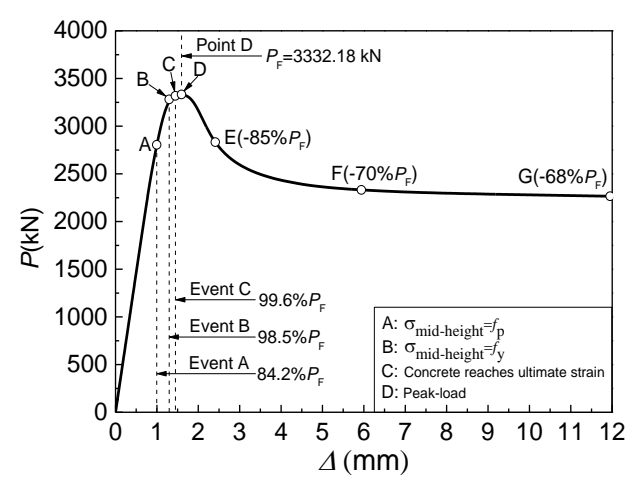

Fig. 8 Load-longitudinal displacement curve of the representative model

\subsection{Longitudinal stress of concrete}

Fig. 2 showed that the crushed positions of the core concrete coincided with the positions where the outward buckling of steel tubes occurred, indicating that these positions along the column height were greatly related to the stress states of the core concrete. Therefore, it is particularly important to examine the longitudinal stress $\left(\sigma_{1}\right)$ distribution in concrete.

The $\sigma_{1}$ distribution in the concrete corresponding to each event of the typical model is presented in Fig. 9. At event A, $\sigma_{1}$ was concentrated in the corner region at the concrete ends, and the magnitude of $\sigma_{1}$ at this location was larger than that at mid-height of the concrete length $(1 / 2 L)$. After event $\mathrm{A}$, the development of plasticity in the concrete caused lateral expansion, which was gradually restricted by the steel tube. Consequently, the independent actions of the steel tube and concrete were halted; instead, the two materials interacted. Moreover, for a square cross-section, stress concentration tends to be induced at the corner region. At event $\mathrm{B}$, the magnitude of $\sigma_{1}$ near the corner was greater than that in the mid-point at $1 / 2 L$.

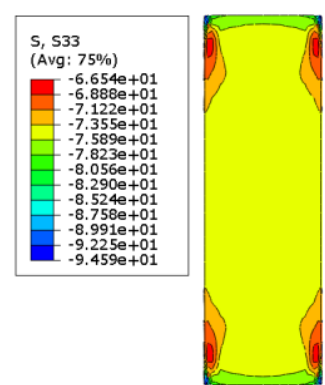

(a) Event $\mathrm{A}$

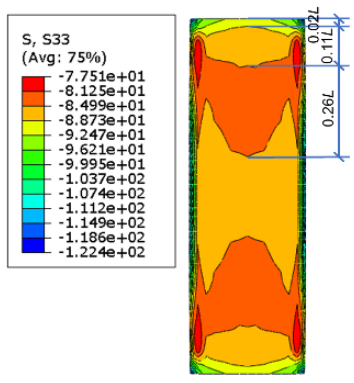

(c) Event C

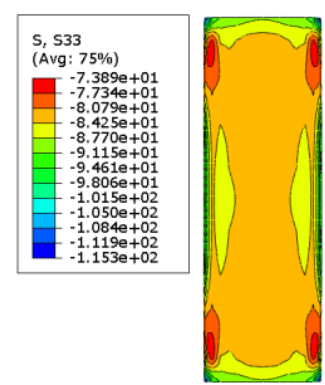

(b) Event B

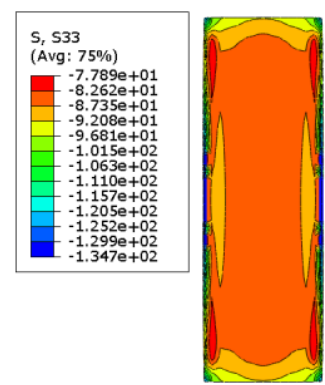

(d) Event D
Fig. 9 Longitudinal stress $\left(\sigma_{1}\right)$ distribution in concrete

At event $\mathrm{C}, \sigma_{1}$ still concentrated at the corner of $1 /{ }_{2} L$. Additionally, as shown in Fig. 9(c), the magnitudes of $\sigma_{1}$ in concrete at $h=1 /{ }_{2} L$ and at $h=0.02$ $L-0.13 L(0.02 L+0.11 L)$ were practically the same. Moreover, the $\sigma_{1}$ value of concrete from the end to $h=0.02 L$ was larger than the $\sigma_{1}$ at other heights. In this event, the $\sigma_{\mathrm{l}}$ value at ${ }^{1} / 2 L$ varied from $-84.99 \mathrm{MPa}\left(-1.04 f_{\mathrm{c}}^{\prime}\right)$ to $-88.73 \mathrm{MPa}$ $\left(-1.08 f_{\mathrm{c}}^{\prime}\right)$ at event $\mathrm{C}("-"$ represents the compressive state). Thereafter, because of the achievement of the ultimate concrete compression strain at event $\mathrm{C}$, $\sigma_{1}$ decreased to the range from $-82.62 \mathrm{MPa}\left(-1.01 f_{\mathrm{c}}^{\prime}\right)$ to $-87.35 \mathrm{MPa}\left(-1.07 f_{\mathrm{c}}^{\prime}\right)$ at event $\mathrm{D}$. Further findings are presented in the following Section.

3.6. Development of contact stress
The steel tube-concrete contact stress at $1 / 2 L$ cross-section of the typicalmodel is given in Fig. 10. The contact stress mainly concentrated at the corner region, whereas there was no contact stress in the flat-plate region. From events $\mathrm{B}$ to $\mathrm{C}, \mathrm{C}$ to $\mathrm{D}$, and $\mathrm{D}$ to $\mathrm{E}$, the maximum contact stresses at the corner increased by $48.4 \%, 53.4 \%$, and $226.8 \%$, respectively. This demonstrates that the contact stress is relatively low before the typical model reaches the peak-load and then develops rapidly after the peak-load. In addition, the numerical results demonstrated that the contact stress gradually propagated from the corners to the flat regions after event E, implying that the flat regions of the square steel tube began to restrain the lateral dilation of concrete at the post-peak stage.

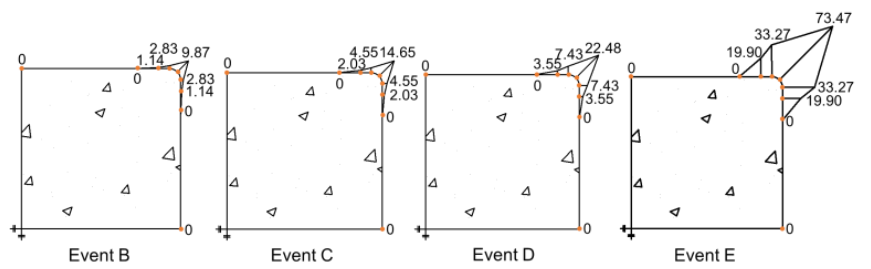

Fig. 10 Steel-concretecontact stress at middle height of typical model (unit: MPa)

As depicted in Fig. 10, the steel tube-concrete contact stress was relatively large at the corner region. To further illustrate the development of the contact stress before the peak-load and analyze its distribution along the column height, the contact stresses in the corner position along the height of the typical column at events $\mathrm{C}$ and $\mathrm{D}$ are provided in Fig. 11.

Based on Fig. 11, at event C, the contact stress at $h=0.31 L(p=16.22$ $\mathrm{MPa})$ was larger than that at $h={ }^{1}{ }_{2} L(p=14.65 \mathrm{MPa})$. This was because the lateral expansion deformation at the corner of the concrete exceeded that of the steel tube, leading to the generation of contact stress, and this phenomenon was more evident at $h=0.31 \mathrm{~L}$. However, at event D, the contact stress at $h=1 / 2 L$ was similar to that at $h=0.31 L$. From events $C$ to $D$, the contact stress at each height gradually increased. It enhanced by $53.4 \%$ at $h=1 / 2 L$, indicating that the steel-concrete coaction performed suitably.

Based on Fig. 9, the $\sigma_{1}$ values of concrete at $h=1 / 2 L$ and $h=0-0.13 L$ were considerably large corresponding to event $\mathrm{C}$, resulting in a large lateral expansion deformation of concrete. Meanwhile, as shown in Fig. 11, the contact stress values at $h=1 / 2 L$ and $h=0-0.13 L$ were also very large, especially, the contact stress was maximum at $h=0.07 L$ at event $\mathrm{C}$. At these positions, the steel tube tended to exhibit outward buckling due to the large contact stress (steel-concrete extrusion stress). Meanwhile, the numerical results confirmed that the outward buckling deformation near the column end $(h=0.07 L)$ was higher than that at $h=1 / 2 L$ before event $\mathrm{D}$, and the outward deformation at $h=1 / 2 L$ evidently enhanced during the descending stage of loading. This is basically consistent with the experimental observation presented in Fig. 3.Consequently, in the tests described in the current study, the outward buckling phenomena occurring in the steel tubes at $1 / 2 L$ and near the column ends (Figs. 2 and 3) can be further explained. The abovementioned findings are obtained within the limited parameter scopes of the columns. Further investigations on the influence of various parameters on the failure modes of the columns remain necessary.

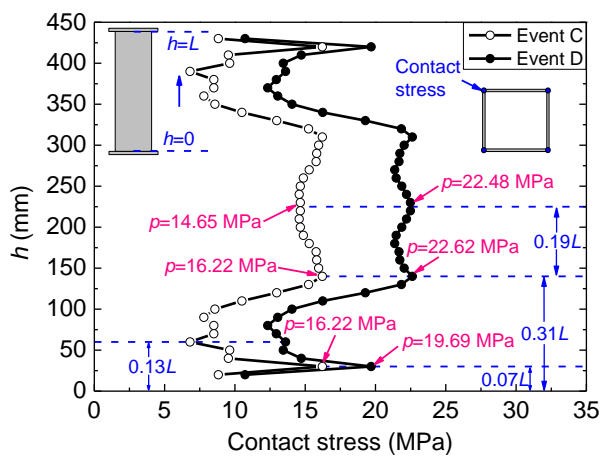

Fig. 11 Contact stress values along the height of the representative model

\subsection{Longitudinal stress distribution of concrete elements in different locations}

The ratios of $\sigma_{\mathrm{lc}-\mathrm{center}}$ and $\sigma_{\mathrm{lc}-\mathrm{outer}}$ to $f_{\mathrm{c}}$ corresponding to various heights of the typical model at its peak-load are presented in Fig. 12, where the values of $\sigma_{\mathrm{lc}-\mathrm{center}}$ and $\sigma_{\mathrm{lc}-\text { outer }}$ are derived from the longitudinal stresses in the concrete 
elements at the center of the effectively confined zone (location a) and at the outer surfacemid-point of the ineffectively confined region (location b), respectively. These ratios reflect the increase in the concrete strength $\left(\triangle f_{\mathrm{c}}^{\prime}\right)$ because of the overall constraint action provided by the steel tube.

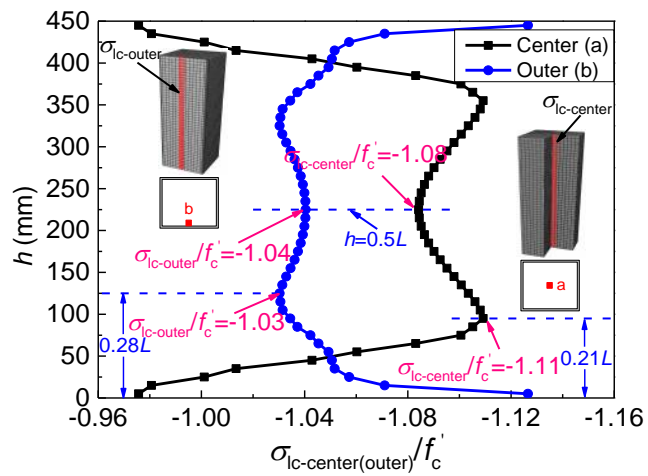

Fig. $12 \sigma_{\text {lc-center(outer) }} / f_{\mathrm{c}}^{\prime}$ values along the height of the typical model

As depicted in Fig. 12, the distributions of these ratios (i.e., $\sigma_{\mathrm{lc}-\mathrm{center}} f_{\mathrm{c}}$ ' and $\left.\sigma_{\mathrm{lc}-\text { outer }} / f_{\mathrm{c}}^{\prime}\right)$ along the height of the column were significantly different. At location a, the longitudinal stresses in concrete elements near the ends of the column were less than those at other heights along the column, whereas an opposite trend was observed at location b. This implies that, at the peak-load, the longitudinal stresses in concrete near the ends of the axially loaded stub column are mainly sustained by the outer surface of concrete. Therefore, the outer surfaces of concrete near the end regions are inclined to be crushed, as shown in Fig. 2.

Additionally, the contact stress at $h=0.5 L$ was practically the maximum at event D (Fig. 11). However, at location a (Fig. 12), $\sigma_{\text {lc-center }} f f_{c}^{\prime}(-1.11)$ at $h=0.21 L$ was slightly higher than that(-1.08) at $h=0.5 L$ ("-" represents compressive state). This is because the steel tube buckles outward at mid-height and near the ends of the column. The steel tubular buckling regions cannot sufficiently confine the concrete, whereas the steel tube regions around the buckling locations continue to effectively constrain the dilation of concrete. Additionally, at location $\mathrm{b}$, the $\sigma_{\mathrm{lc}-\text { outer }} f_{\mathrm{c}}^{\prime}$ values within the range of $0.44 L(1-0.28 L \times 2)$ in the middle of column height were similar (i.e., from -1.03 to -1.04), demonstrating that $\triangle f_{\mathrm{c}}^{\prime}$ in this region was similar.

\section{Parametric study}

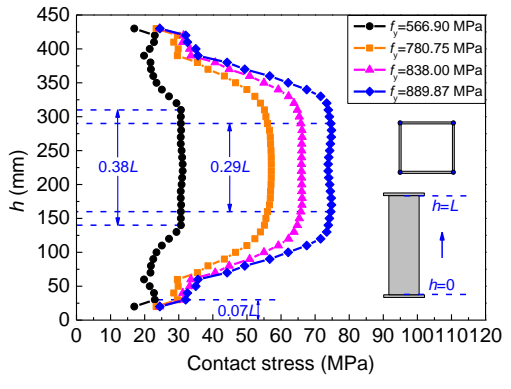

(a) $f_{\mathrm{cu}}=70 \mathrm{MPa}$

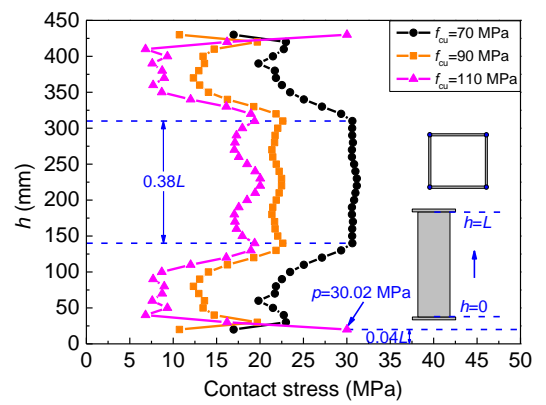

(a) $f_{\mathrm{y}}=566.90 \mathrm{MPa}$

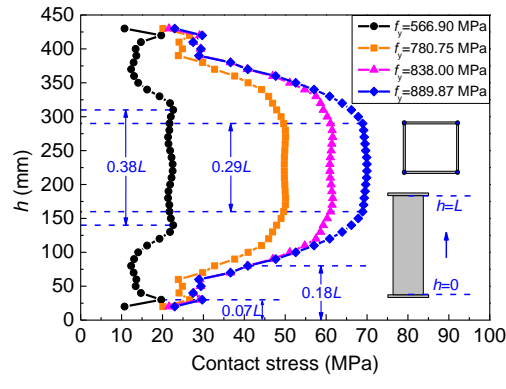

(b) $f_{\mathrm{cu}}=90 \mathrm{MPa}$

Fig. 13 Effect of $f_{\mathrm{y}}$ on contact stress

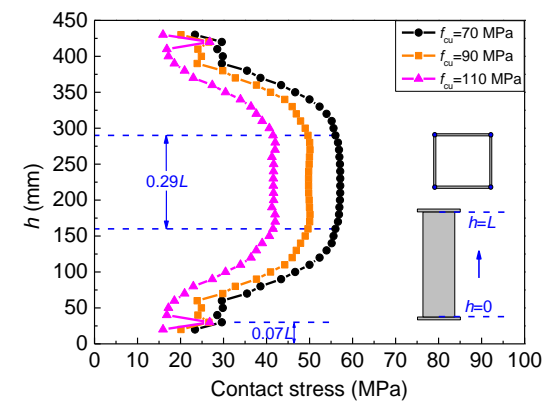

(b) $f_{\mathrm{y}}=780.75 \mathrm{MPa}$
The higher contact stress values indicate that the steel-concrete extrusion forces and confinements that exist in columns are greater. The confinement effect is important to improve the performance of composite columns. Thus, the steel tube-concrete contact stresses at the corners at various heights along the columns matching the peak-loads are presented in Section 4.1.Moreover, Section 4.2 illustrates the $\sigma_{\mathrm{lc}-\mathrm{center}} / f_{\mathrm{c}}^{\prime}$ variation, which helps to understand $\Delta f_{\mathrm{c}}^{\prime}$ caused by the overall restraining effect of the steel tube on concrete.

\subsection{Contact stress along column height}

\subsubsection{Effect of yield strength of steel}

The influence of $f_{\mathrm{y}}(566.90 \mathrm{MPa}$ to $889.87 \mathrm{MPa})$ on the contact stress of HCFHSST columns with $B=150 \mathrm{~mm}, \alpha=0.148, L=450 \mathrm{~mm}$, and $f_{\mathrm{cu}}=70$ $\mathrm{MPa}-110 \mathrm{MPa}$ is shown in Fig. 13. Although it is observed in Fig. 13(b) and (c) that the contact stresses practically remain unchanged within the range $h=0-0.18 L$ as $f_{\mathrm{y}}$ increases from 838.00 to $889.87 \mathrm{MPa}$, those at various heights generally increase with $f_{\mathrm{y}}$. In addition, as presented in Fig. 13(b), for the models with $f_{\mathrm{y}}=566.90 \mathrm{MPa}$, the contact stress slightly changes within the range of $0.38 \mathrm{~L}$ in the middle of the column, indicating that the constraint action is similar in this range. However, as $f_{\mathrm{y}}$ increases, the range decreases from $0.38 L$ to $0.29 L$, illustrating that the constraint afforded by the steel tube on concrete accumulates toward the mid-height section with an increase in $f_{\mathrm{y}}$.

\subsubsection{Effect of concrete strength}

The influence of $f_{\text {cu }}$ (70 MPa to $110 \mathrm{MPa}$ ) on the contact stress of models with $B=150 \mathrm{~mm}, \alpha=0.148, L=450 \mathrm{~mm}$, and $f_{\mathrm{y}}=566.90 \mathrm{MPa}-889.87 \mathrm{MPa}$ is shown in Fig. 14. Overall, the contact stress along the column height gradually decreases as $f_{\mathrm{cu}}$ increases, demonstrating that the constraint action reduces with increasing $f_{\text {cu. }}$. Additionally, as $f_{\text {cu }}$ increases from 70 to $110 \mathrm{MPa}$, the contact stress mainly concentrates within the range of $0.38 \mathrm{~L}$ in the middle of the column for the models with $f_{\mathrm{y}}=566.90 \mathrm{MPa}$, while it mainly concentrates within the range of $0.29 L$ for the models with $f_{\mathrm{y}}=780.75$ MPa-889.87 MPa. The results show that, compared with the effect of $f_{\mathrm{y}}$ on the concentration range of contact stress in the middle of the column, the influence of $f_{\text {cu }}$ is relatively insignificant.

It should be noted that the contact stress near the end of column is relatively high under the two following conditions.

As shown in Figs. 13 and 14, at peak-loads, the contact stress in the middle of the column is greater than that at the end region (except for the model with $\alpha=0.148, f_{\mathrm{y}}=566.90 \mathrm{MPa}$, and $f_{\mathrm{cu}}=110 \mathrm{MPa}$ ). However, based on the numerical results, the contact stress at $h=0.07 \mathrm{~L}$ remains close to that at the middle of the column before each column reaches the peak-load despite the variations in material strengths. This phenomenon is similar to that at event $\mathrm{C}$ (Fig. 11). 
The data in Fig. 14 were employed to investigate the ratio of the contact stress at $h=0.07 L\left(p_{1}\right)$ to that at the mid-height of the column $\left(p_{2}\right)$. For the models $w i t h f_{\mathrm{y}}=889.87,780.75$, and $566.90 \mathrm{MPa}$, at the peak-loads, the ratios of $p_{1}$ to $p_{2}$ were $0.43,0.52$, and 0.74 , respectively, when $f_{\mathrm{cu}}=70 \mathrm{MPa}$, and they were $0.51,0.64$, and 0.81 , respectively, when $f_{\mathrm{cu}}=110 \mathrm{MPa}$. It is found that, the ratio of $p_{1}$ to $p_{2}$ increases with $f_{\text {cu }}$ when $f_{\mathrm{y}}$ is constant, whereas it increases with the decrease of $f_{\mathrm{y}}$ when $f_{\text {cu }}$ is constant. Furthermore, as mentioned above, the confinement coefficient [34] decreases as $f_{\mathrm{y}}$ decreases and as $f_{\mathrm{cu}}$ increases.

\subsubsection{Effect of steel ratio}

The steel tubular wall-thickness $(t=5,6$, and $7 \mathrm{~mm})$ was varied to obtain several steel ratios $(\alpha=0.148,0.182$, and 0.217). The influence of $\alpha$ (0.148-0.217) on the contact stress of models with $B=150 \mathrm{~mm}, L=450 \mathrm{~mm}$, $f_{\mathrm{y}}=566.90 \mathrm{MPa}-889.87 \mathrm{MPa}$, and $f_{\mathrm{cu}}=90 \mathrm{MPa}$ is shown in Fig. 15. It can be observed that the contact stress increases when $\alpha$ increases from 0.148 to 0.182 . However, the increase in contact stress is small when $\alpha$ increases from 0.182 to 0.217 , as shown in Fig. 15 (b). In particular, the decrease in the contact stress at $h=1 / 2 L$ is presented in Fig. 15 (a) and (c). This may be attributed to the fact that the $\alpha$ value of 0.217 exceeds the normal steel ratio range (4\%-20\%), according to Ref. [38] and provisions of GB 50936 [5]. Hence, although the column confinement factor $(\xi)$ increases with $\alpha$, the improvement in the contact stress (confinement effect) is less effectivewhen $\alpha$ exceeds the normal range. Additionally, the influence of $\alpha$ on contact stress is smaller than that of material strengths.

4.2. Longitudinal stress distribution of concrete in the center of strongly confined zone

To further investigate the concrete stress variation at the center of the strongly confined zone. The influences of several key parameters on the values of $\sigma_{\text {lc-center }} / f_{\mathrm{c}}^{\prime}$ at the peak-loads are depicted in Fig. 16. Fig. 16(a) shows the effect of $f_{\mathrm{y}}$ on $\sigma_{\mathrm{lc}-\mathrm{center}} / f_{\mathrm{c}}^{\prime}$. The $\sigma_{\mathrm{lc}-\mathrm{center}} / f_{\mathrm{c}}^{\prime}$ value at $h=0.5 \mathrm{~L}$ increases by $6.3 \%$ when $f_{\mathrm{y}}$ increases from $566.90 \mathrm{MPa}$ to $838.00 \mathrm{MPa}$, whereas it slightly decreases by $0.4 \%$ when $f_{\mathrm{y}}$ increases from $838.00 \mathrm{MPa}$ to $889.87 \mathrm{MPa}$. The main reason is that the steel tubular buckling tends to occur in the axially loaded column with a relatively high $f_{\mathrm{y}}$ value when the values of $B$ and $t$ are constant, as per AISC 360 [4]. Consequently, the enhancement in $\sigma_{\text {lc-center }} / f_{\mathrm{c}}^{\prime}$ becomes less efficient. From the perspective of increasing $\sigma_{\text {lc-center }} / f_{\mathrm{c}}^{\prime}$, the steel with $f_{\mathrm{y}}=838.00 \mathrm{MPa}$ is a separation point within the limited parameter scopes.

The influence of $f_{\text {cu }}$ on $\sigma_{\text {lc-center }} / f_{\mathrm{c}}^{\prime}$ is illustrated in Fig. $16(\mathrm{~b})$. The $\sigma_{\text {lc-center }} / f_{\mathrm{c}}^{\prime}$ values decrease as $f_{\text {cu }}$ increases because of the reduction in the constraint factor $(\xi)$. As $f_{\text {cu }}$ increases from 70 to $90 \mathrm{MPa}$, and from 90 to $110 \mathrm{MPa}$, the $\sigma_{\text {lc-center }} / f_{\mathrm{c}}^{\prime}$ values at $h=0.5 \mathrm{~L}$ decrease by $4.2 \%$ and $1.4 \%$, respectively. This indicates that the reduction becomes limited as $f_{\text {cu }}$ increases.

The effect of $\alpha$ on $\sigma_{\text {lc-center }} / f_{\mathrm{c}}^{\prime}$ is provided in Fig. 16(c). It can be observed that the values of $\sigma_{\mathrm{lc}-\mathrm{center}} / f_{\mathrm{c}}^{\prime}$ within the range of $h=0-0.21 \mathrm{~L}$ are similar as $\alpha$ increases. The $\sigma_{\mathrm{lc}-\mathrm{center}} / f_{\mathrm{c}}^{\prime}$ value at $h=0.5 \mathrm{~L}$ increases by $1.2 \%$ as $\alpha$ increases from 0.148 to 0.182 , while it decreases by $0.2 \%$ as $\alpha$ increases from 0.182 to 0.217 . Although it is widely known that the confined effect increases with the steel ratio, it can be found that, when the normal steel ratio $(20 \%)$ specified in GB 50936 [5] and reported in Ref. [38] is exceeded, the enhancement in $\sigma_{\text {lc-center }} / f_{\mathrm{c}}^{\prime}$ is less effective, which is similarly observed in Fig. 15.

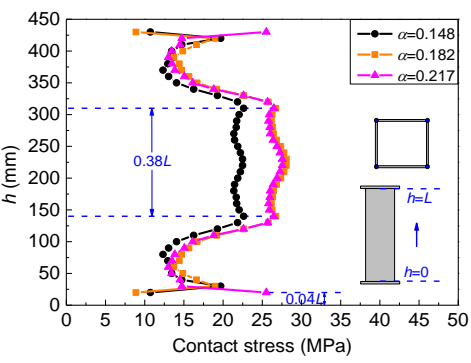

(a) $f_{\mathrm{y}}=566.90 \mathrm{MPa}$

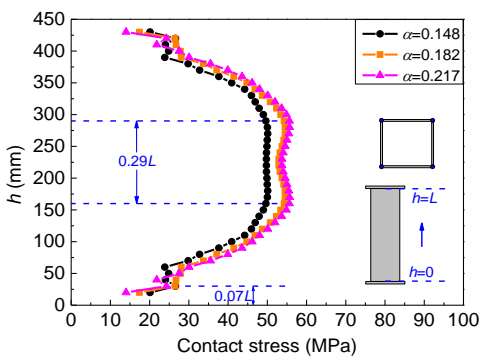

(b) $f_{\mathrm{y}}=780.75 \mathrm{MPa}$

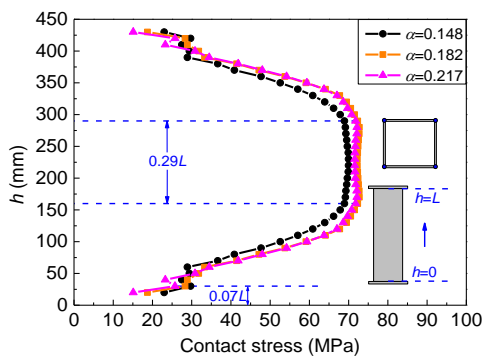

(c) $f_{\mathrm{y}}=889.87 \mathrm{MPa}$

Fig. 15 Effect of $\alpha$ on contact stress

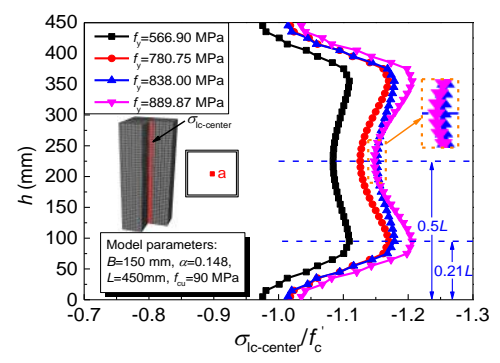

(a) Effect of $f_{\mathrm{y}}$ on $\sigma_{\mathrm{lc}-\mathrm{center}} / f_{\mathrm{c}}$

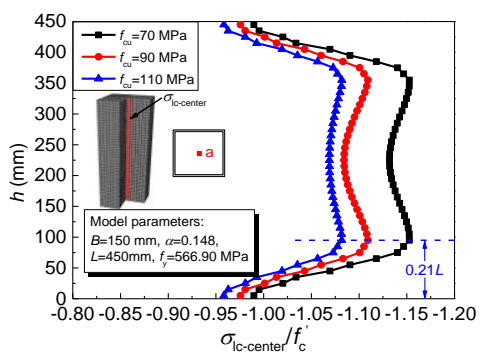

(b) Effect of $f_{\text {cu }}$ on $\sigma_{\text {lc-center }} / f_{\mathrm{c}}$

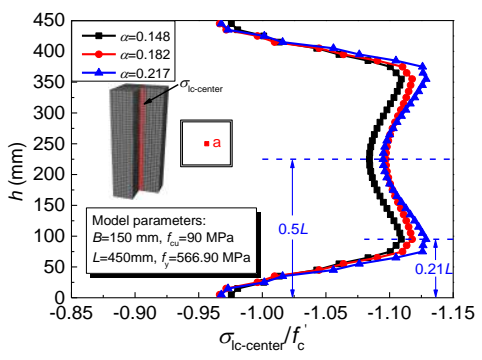

(c) Effect of $\alpha$ on $\sigma_{\mathrm{lc}-\mathrm{center}} / f_{\mathrm{c}}$

Fig. 16 Effects of $f_{\mathrm{y}} f_{\mathrm{cu}}$, and $\alpha$ on $\sigma_{\mathrm{lc}-\mathrm{center}} / f_{\mathrm{c}}$

\section{Calculation of peak-loads}

\subsection{Establishment of high-strength CFST database}

The data on the available 162 test samples and 8 experimental specimens tested in the current study were collected to establish a database of high-strength CFST stub columns. The material strength distributions of the collected CFST samples are shown in Fig. 17.The database (Table 3) consists of information on 48 axially loaded CFST stub columns using conventional-strength steel and high-strength concrete (CSS-HSC), 39 CFSTs adopting high-strength steel and conventional-strength concrete (HSS-CSC), and 83 columns using high-strength steel and high-strength concrete (HSS-HSC). The characteristics of the selected sample data are similar to those of the current investigation and a previous study of the authors [31]. Data on some CFSTs with noncompact or slender sections were also included in this database. As listed in Table 3, both square and rectangular samples were collected, where $B=60 \mathrm{~mm}-300 \mathrm{~mm}, H=60 \mathrm{~mm}-300 \mathrm{~mm}, B / H=1-2$, $t=1.87 \mathrm{~mm}-9.45 \mathrm{~mm}$, slenderness coefficient [4] $\left(\lambda_{\text {coeff }}=b / t\left(f_{\mathrm{y}} / E_{\mathrm{s}}\right)^{1 / 2}\right)=$
0.5-4.9, $\quad b=B-2 t, \quad L / H=2.4-6.1, \quad f_{\mathrm{y}}=250^{\mathrm{d}} \quad \mathrm{MPa}-889.87 \quad \mathrm{MPa}, \quad$ and $f_{\mathrm{c}}$ $\left(f_{\mathrm{cu}}\right)=21^{\mathrm{b}}-121.6^{\mathrm{c}} \mathrm{MPa}$.

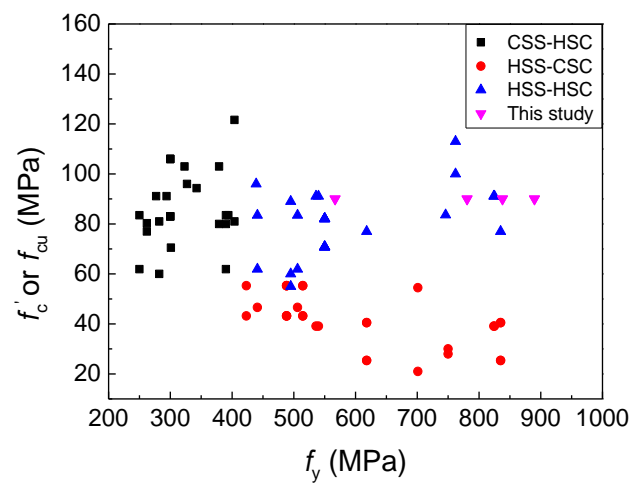

Fig. 17 Strength distributions of materials used in collected test samples 
Table 3

Test database of CFST stub columns using high-strength materials

\begin{tabular}{|c|c|c|c|c|c|c|c|c|}
\hline Source & NS & Type & $B(\mathrm{~mm})$ & $H(\mathrm{~mm})$ & $\lambda_{\text {coeff }}$ & $L / H$ & $f_{\mathrm{y}}(\mathrm{MPa})$ & $f_{\mathrm{c}}^{\prime}$ or $f_{\mathrm{cu}}(\mathrm{MPa})$ \\
\hline Lee et al.[11] & 1 & \multirow{9}{*}{ CSS-HSC } & 300 & 300 & 2.3 & 3 & 301 & $70.5^{\mathrm{a}}$ \\
\hline Sakino et al. [39] & 4 & & $148-215$ & $148-215$ & $1.2-1.7$ & 3 & $262-294$ & $77-91.1^{\mathrm{b}}$ \\
\hline Ibañez et al. [24] & 1 & & 125 & 125 & 1.2 & 2.4 & 342.6 & $94.3^{\mathrm{b}}$ \\
\hline Liu and Gho[40] & 14 & & $120-220$ & $100-200$ & $0.7-1.4$ & $3-5.4$ & 300 & $83-106^{\mathrm{b}}$ \\
\hline Young and Ellobody[41] & 5 & & $150.5-197.6$ & $80.4-150.6$ & $1.8-2.4$ & $3.0-6.0$ & $250-394^{d}$ & $61.9-83.5^{\mathrm{b}}$ \\
\hline Yu et al. [42] & 4 & & 100 & 100 & 2.3 & 3 & 404 & $121.6^{\mathrm{c}}$ \\
\hline Cederwall et al.[43] & 5 & & 120 & 120 & $0.5-0.6$ & 4.2 & $323-390$ & $80-103^{b}$ \\
\hline Han et al. [44] & 14 & & $60-250$ & $60-250$ & $1.1-4.9$ & 3 & $282-404$ & $60-81^{\mathrm{c}}$ \\
\hline Uy [45] & 4 & & $110-160$ & $110-160$ & $1.2-1.8$ & 3 & 750 & $28-30^{\mathrm{b}}$ \\
\hline Sakino et al. [39] & 16 & \multirow{4}{*}{ HSS-CSC } & $120-211$ & $120-211$ & $1.1-1.7$ & 3 & $536-835$ & $25.4-40.5^{\mathrm{b}}$ \\
\hline Aslani et al. [15] & 5 & & $110-160$ & $110-160$ & $1.2-1.8$ & $2.7-2.8$ & 701 & $21-54.5^{\mathrm{b}}$ \\
\hline Du et al. [6] & 6 & & $150-203$ & $101-150$ & $0.8-1.3$ & $3.0-6.0$ & 488.38 & $43.2-55.3^{\mathrm{c}}$ \\
\hline Young and Ellobody [41] & 2 & & $140.2-150.5$ & $80.1-150.5$ & $1.2-2.0$ & $3.0-5.2$ & $441-506^{\mathrm{d}}$ & $46.6^{\mathrm{b}}$ \\
\hline Du et al. [46] & 6 & \multirow{11}{*}{ HSS-HSC } & $120-182$ & $100-122$ & $1.0-1.5$ & $3.6-4.6$ & $423.2-514.5$ & $43.2-55.3^{\mathrm{c}}$ \\
\hline Lee et al. [11] & 1 & & 300 & 150 & 3.5 & 6 & 746 & $83.6^{\mathrm{a}}$ \\
\hline Sakino et al. [39] & 8 & & $119-211$ & $119-211$ & $1.1-1.7$ & 3 & $536-835$ & $77-91.1^{\mathrm{b}}$ \\
\hline Liu [47] & 22 & & $106-190$ & $80-140$ & $1.2-2.3$ & $3-6$ & 495 & $60-89^{b}$ \\
\hline Khan et al. [7] & 6 & & $124.4-199.0$ & $124.4-199.0$ & $1.4-2.4$ & $3.4-5.3$ & 762 & $100-113^{\mathrm{b}}$ \\
\hline Liu and Gho[40] & 12 & & $120-190$ & $90-130$ & $1.4-2.3$ & $3-6$ & 495 & $55^{\mathrm{b}}$ \\
\hline Young and Ellobody [41] & 4 & & $140.2-150.6$ & $80.0-150.6$ & $1.2-2.0$ & $3.0-5.3$ & $441-506^{\mathrm{d}}$ & $61.9-83.5^{\mathrm{b}}$ \\
\hline Cederwallet al.[43] & 1 & & 120 & 120 & 0.6 & 4.2 & 439 & $96^{\mathrm{b}}$ \\
\hline Liu et al. [48] & 21 & & $100.3-200.2$ & $80.1-181.2$ & $1.2-2.4$ & $3.0-6.1$ & 550 & $70.8-82.1^{\mathrm{c}}$ \\
\hline This study & 8 & & 150 & 150 & $1.5-1.9$ & 3 & $566.9-889.87$ & $90^{c}$ \\
\hline Total & 170 & & $60-300$ & $60-300$ & $0.5-4.9$ & $2.4-6.1$ & $250^{\mathrm{d}}-889.87$ & $21^{\mathrm{b}}-121.6^{\mathrm{c}}$ \\
\hline
\end{tabular}

Note: NS $=$ number of the collected samples; $B \geq H$; for concrete strength, ${ }^{\text {a }}$ indicates the 100 -mm diameter concrete cylinder strength; ${ }^{\mathrm{b}}$ represents the standard cylinder strength; ${ }^{\mathrm{c}}$ denotes the concrete cube strength obtained from tests on $150 \times 150 \times 150-\mathrm{mm}^{3}$ blocks; ${ }^{\mathrm{d}}$ indicates the yield strength obtained from the hollow stub column tests.

\subsection{Comparisons among various design codes}

Eurocode 4 [3] regulates that the peak-load $\left(N_{\mathrm{pl}, \mathrm{Rk}}\right)$ of the concentrically compressed square CFST stub column can be computed according to Eq. (6), which is presented as follows based on the superposition method:

$N_{\mathrm{pl}, \mathrm{Rk}}=f_{\mathrm{y}} A_{\mathrm{s}}+f_{\mathrm{c}}^{\prime} A_{\mathrm{c}}$

According to the tube slenderness (width-to-thickness ratio, i.e., b/t) classifications listed in Table I1.1a of AISC 360 [4], the ultimate capacities $\left(P_{\mathrm{n} 0}\right)$ of CFST stub columns with various sections are determined using Eqs. (7)-(10).In these equations, at the peak-load, the strengths of steel $\left(f_{\mathrm{y}}\right)$ and concrete $\left(f_{\mathrm{c}}^{\prime}\right)$ are not exerted simultaneously, which is different from Eurocode 4 [3]. A coefficient of 0.85 is adopted in AISC 360 [4] to consider the reduction in the concrete strength of rectangular CFSTs with compact sections, becausethe strength of core concrete in CFSTs differs from the standard concrete strength, and the initial load eccentricity exists in the columns [12]. As provided in Eq. (7), for noncompact columns with $\lambda=\lambda_{\mathrm{r}}$, the ultimate capacityis $P_{\mathrm{n} 0}=P_{\mathrm{y}}$, and $P_{\mathrm{y}}$ is given in Eq. (9), indicating that although steel experiences local buckling, the steel stress can also attain $f_{\mathrm{y}}$. However, the concrete stress $\left(0.70 f_{\mathrm{c}}^{\prime}\right)$ is less than that in Eq. (8), because the confinement generated by the noncompact sectional steel tube is inadequate. Moreover, when calculating the peak-loads of slender columns, the critical buckling stress $\left(F_{\text {cr }}\right)$ is used instead of $f_{\mathrm{y}}$ in AISC 360 [4] due to the elastic buckling of the steel tube, and the concrete stress can reach $0.7 f_{\mathrm{c}}^{\prime}$, as expressed in Eq. (7).

$P_{\mathrm{n} 0}=\left\{\begin{array}{lr}P_{\mathrm{p}} & \text { Compact sections }\left(\lambda \leq \lambda_{\mathrm{p}}\right) \\ P_{\mathrm{p}}-\frac{P_{\mathrm{p}}-P_{\mathrm{y}}}{\left(\lambda_{\mathrm{r}}-\lambda_{\mathrm{p}}\right)^{2}}\left(\lambda-\lambda_{\mathrm{p}}\right)^{2} & \text { Noncompact sections }\left(\lambda_{\mathrm{p}}<\lambda \leq \lambda_{\mathrm{r}}\right) \\ F_{\mathrm{cr}} A_{\mathrm{s}}+0.7 f_{\mathrm{c}}^{\prime} A_{\mathrm{c}} & \text { Slender sections }\left(\lambda>\lambda_{\mathrm{r}}\right)\end{array}\right.$

$P_{\mathrm{p}}=f_{\mathrm{y}} A_{\mathrm{s}}+0.85 f_{\mathrm{c}}^{\prime} A_{\mathrm{c}}$

$P_{\mathrm{y}}=f_{\mathrm{y}} A_{\mathrm{s}}+0.70 f_{\mathrm{c}}^{\prime} A_{\mathrm{c}}$

$F_{\mathrm{cr}}=9 E_{\mathrm{s}} /(b / t)^{2}$ where $\lambda$ is the tube slenderness ratio, $\lambda=b / t, \lambda_{\mathrm{p}}=2.26 \cdot\left(E_{\mathrm{s}} / f_{\mathrm{y}}\right)^{1 / 2}$, and $\lambda_{\mathrm{l}}=3.00 \cdot\left(E_{\mathrm{s}} f_{\mathrm{y}}\right)^{1 / 2}$.

Compared with Eurocode 4 [3] and AISC 360 [4], the confined action of the steel tube is considered in GB 50936 [5] on the basis of the unified theory. The peak-load $\left(N_{0}\right)$ calculation equation is given as follows:

$N_{0}=A_{\mathrm{sc}} f_{\text {scy }}$

$f_{\text {scy }}=\left(1.212+B \theta+C \theta^{2}\right) f_{\mathrm{ck}}$

$\theta=\frac{A_{\mathrm{s}} f_{\mathrm{y}}}{A_{\mathrm{c}} f_{\mathrm{ck}}}$

$B=0.131 f_{\mathrm{y}} / 235+0.723$

$C=-0.070 f_{\mathrm{ck}} / 20+0.026$

where $f_{\text {scy }}$ is the compressive strength of the composite section; $A_{\text {sc }}$ is the area of the cross-section; and $\theta$ is the confined factor.

The peak-loads of the axially loaded CFST stub columns were calculated by utilizing the formulas provided in Eurocode 4 [3], AISC 360 [4], and GB 50936 [5]. The results are summarized in Table 4 and shown in Figs. 18-21. The concrete strengths specified in these design codes were determined based on the respective regulation and Ref. [31].

Table 4

Peak-load calculations

\begin{tabular}{|c|c|c|c|c|c|c|c|}
\hline \multirow{2}{*}{ Type } & \multirow{2}{*}{ NS } & \multicolumn{2}{|c|}{ Eurocode 4} & \multicolumn{2}{|c|}{ AISC 360} & \multicolumn{2}{|c|}{ GB 50936} \\
\hline & & Average & $\mathrm{COV}$ & Average & $\mathrm{COV}$ & Average & $\mathrm{COV}$ \\
\hline CSS-HSC & 48 & 1.04 & 0.07 & 0.91 & 0.12 & 1.00 & 0.06 \\
\hline HSS-CSC & 39 & 0.96 & 0.09 & 0.93 & 0.09 & 0.92 & 0.11 \\
\hline HSS-HSC & 83 & 0.97 & 0.07 & 0.91 & 0.07 & 0.94 & 0.06 \\
\hline All test samples & 170 & 0.99 & 0.08 & 0.91 & 0.09 & 0.95 & 0.08 \\
\hline
\end{tabular}

Note: NS = number of collected samples; Average $=$ mean ratio value of calculation to test results; and $\mathrm{COV}=$ Coefficientof Variation. 


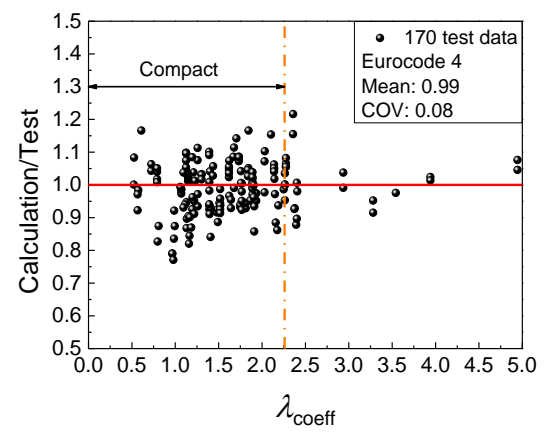

(a) Eurocode 4

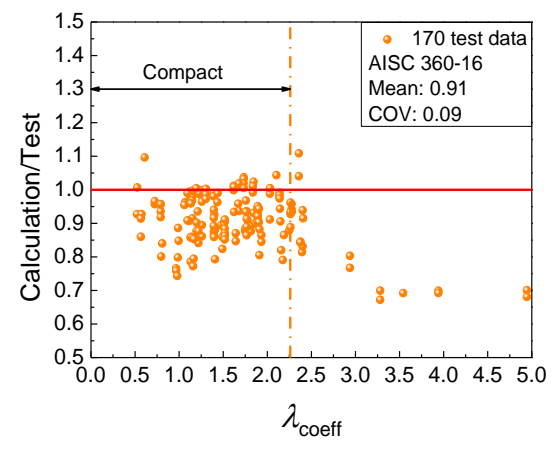

(b) AISC 360

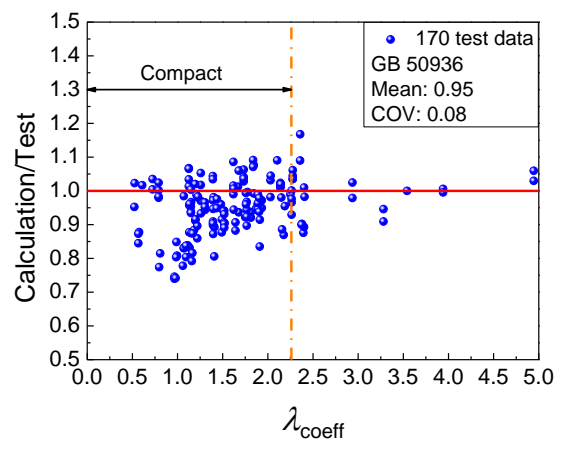

(c) GB 50936

Fig. 18 Ultimate bearing capacity evaluations of collected 170 test samples

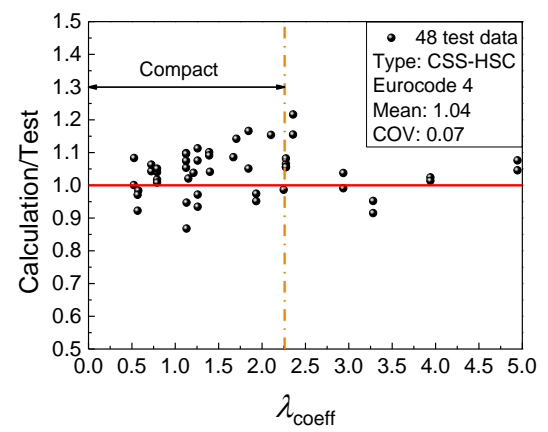

(a) Eurocode 4

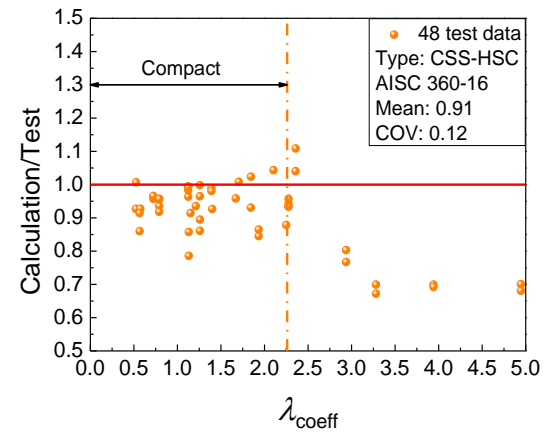

(b) AISC 360

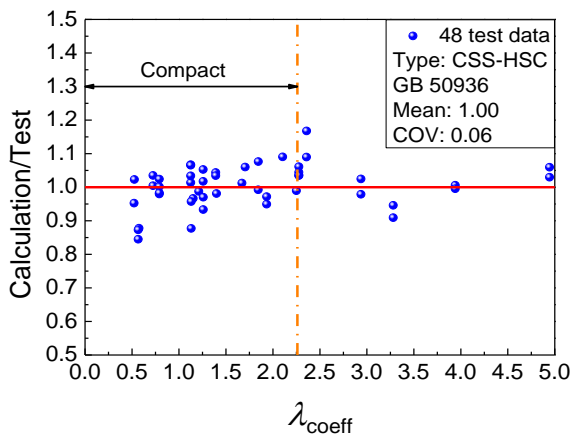

(c) GB 50936

Fig. 19 Ultimate bearing capacity evaluations of CSS-HSC columns

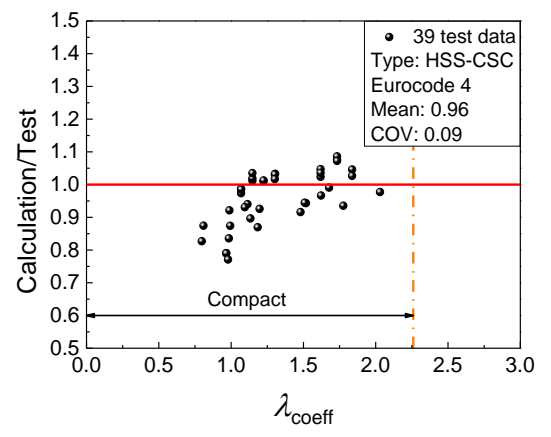

(a) Eurocode 4

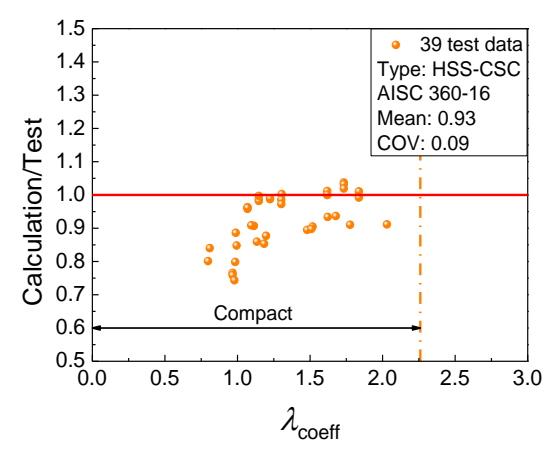

(b) AISC 360

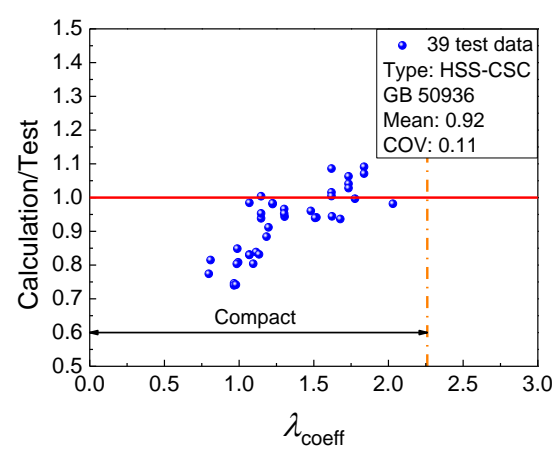

(c) GB 50936

Fig. 20 Ultimate bearing capacity evaluations of HSS-CSC columns

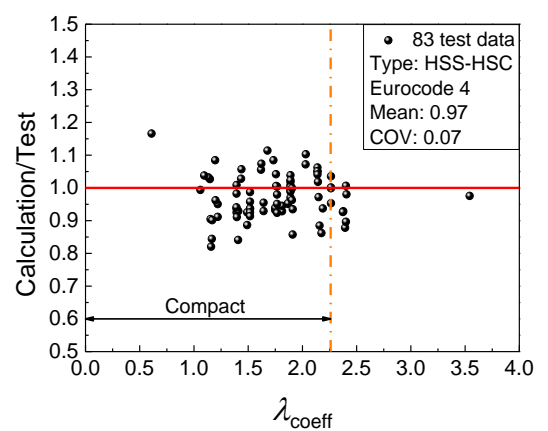

(a) Eurocode 4

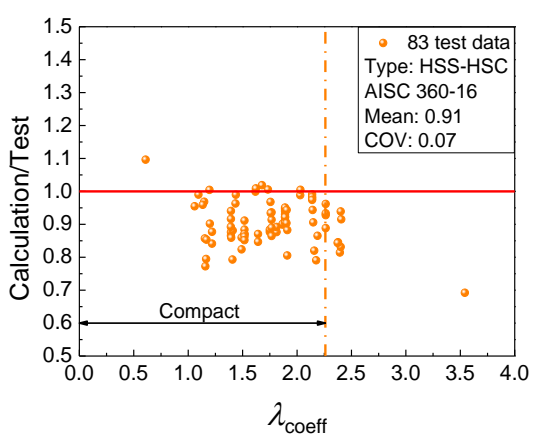

(b) AISC 360

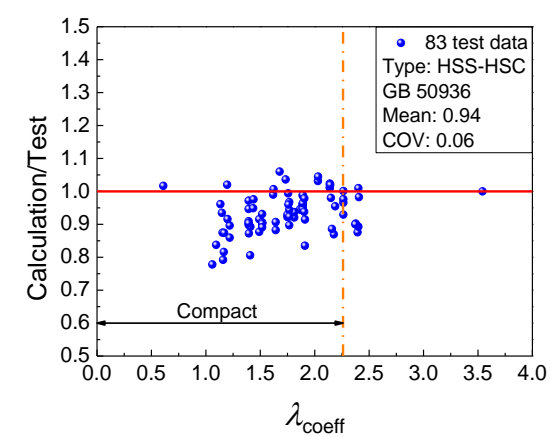

(c) GB 50936

Fig. 21 Ultimate bearing capacity evaluations of HSS-HSC columns

According to Table 4 and Fig. 18, the calculations of Eurocode 4 [3] are overall closer to the test results (average ratio of calculation to test equals to 0.99) than those of other codes.Compared with Eurocode 4 [3], the predictions of AISC 360 [4] are conservative. In particular, for columns with slender cross-sections, AISC 360 [4] presents the most conservative trend (Fig. 18) compared with other design codes, due to the consideration of material strength reductions.Additionally, compared with AISC 360 [4], GB 50936 [5] provides better predictions on average, with a smaller scatter, due to the consideration of confined action. 


\subsection{Further discussions on utilization efficiency of material strengths}

The utilization efficiency of material strengths is discussed in this Section based on further data analyses (Figs. 19 to 21). The calculation results of Eurocode 4 [3] are mainly used for comparison to clarify the corresponding findings, because Eurocode 4 [3] considers that the strengths of steel $\left(f_{\mathrm{y}}\right)$ and concrete $\left(f_{c}^{\prime}\right)$ can be simultaneously exerted when the columns achieve the peak-loads.

As demonstrated in Table 4 and Fig. 19, when calculating the peak-loads of CFST stub columns with CSS-HSC, the calculations of Eurocode 4 [3] are unsafe because of the following reasons. For the CSS-HSC cases, the CSS provides insufficient confinements on the HSC; consequently, steel tubular buckling may occur before yielding, and the load sustained by the steel tube decreases. Finally, the CFST column and concrete achieve their ultimate strengths simultaneously; hence, at the ultimate load, the longitudinal stress in the steel tube is lower than $f_{\mathrm{y}}$. Additionally, since the HSC is a more brittle material compared with CSC, its premature crushing may prevent the complete development of the concrete strength.

When evaluating the peak-loads of CFSTs with HSS-CSC, although Eurocode 4 [3] presents conservative predictions (Table 4 and Fig. 20) on average, more numbers of unsafe sample data points can be found in its calculations [3] than in the predictions of other design codes (Fig. 20). This is because the CSC tends to be crushed before the peak-load of the column is reached. Then, the concrete dilates rapidly, resulting in steel tubular premature buckling. Thereafter, steel strength may not be adequately exerted.

Although the columns using HSS can provide more sufficient confinement to the inner HSC than columns utilizing CSS, numerous unconservative sample data points are also found in the predictions of Eurocode 4 [3], as shown in Fig. 21. This is because steel tubular buckling tends to occur in the CFST column with a higher $f_{\mathrm{y}}$, thereby reducing the steel strength. Additionally, the size effect influences the property of HSC, which means that the maximum stress in the HSC is lower than that obtained by thecylindrical concrete test (i.e., $f_{\mathrm{c}}^{\prime}$ ).

\subsection{Further discussions on peak-load predictions of compact CFSTs}

As specified in AISC 360 [4], the steel yield strength $\left(f_{\mathrm{y}}\right)$ can be fully exerted in the CFST stub columns with compact sections $\left(b / t \leq 2.26 \cdot\left(E_{\mathrm{s}} / f_{\mathrm{y}}\right)^{1 / 2}\right)$. However, the local buckling effect is more pronounced in columns with noncompact and slender sections [4]. Given this background, the peak-loads of compact sectional CFSTs should be further assessed to derive useful insights for engineering applications. The detailed results are tabulated in Table 5 .

Based on Table 5, for predicting the peak-loads of compact CFST stub columns, Eurocode 4 [3] overall presents better results followed by codes GB 50936 [5] and AISC 360 [4], respectively. However, in the CSS-HSC cases, the predictions of Eurocode 4 [3] are unconservative, as similarly evidenced by the results listed in Table 4.In general, it is worth noting that the predictions of AISC 360 [4] and GB 50936 [5] are similar. Both codes yield conservative calculations, and the overall errors between the two are within 4\%. Although GB 50936 [5] conforms better with the test results than AISC 360 [4], the former yields more unconservative calculations for compact CFST stub columns, as presented in Figs. 18-21. In terms of safety, AISC 360 [4] can be utilized in the field applications of compact CFST stub columns using high-strength materials.

\section{Table 5}

Peak-load calculations of compact CFSTs

\begin{tabular}{|c|c|c|c|c|c|c|c|}
\hline \multirow{2}{*}{ Type } & \multirow{2}{*}{ NS } & \multicolumn{2}{|c|}{ Eurocode 4} & \multicolumn{2}{|c|}{ AISC 360} & \multicolumn{2}{|c|}{ GB 50936} \\
\hline & & Average & $\mathrm{COV}$ & Average & $\mathrm{COV}$ & Average & $\mathrm{COV}$ \\
\hline CSS-HSC & 34 & 1.04 & 0.07 & 0.94 & 0.06 & 0.99 & 0.06 \\
\hline HSS-CSC & 39 & 0.96 & 0.09 & 0.93 & 0.09 & 0.92 & 0.11 \\
\hline HSS-HSC & 72 & 0.98 & 0.07 & 0.91 & 0.07 & 0.94 & 0.07 \\
\hline All test samples & 145 & 0.99 & 0.08 & 0.92 & 0.07 & 0.95 & 0.08 \\
\hline
\end{tabular}

Note: NS = number of the collected samples; Average = mean ratio value of calculation to test results; $\mathrm{COV}=$ Coefficientof Variation .

\section{Conclusions}

The use of high-strength materials in CFST columns has promising prospects. High-strength square CFST columns generally exhibit complex performances including local and post-local buckling behaviors, brittle concrete crushing, and inhomogeneous steel-concrete interaction. To systematically reveal these mechanical responses, an experimental study was performed on eight specimens considering variations in the yield strength of steel. Numerical investigations were also conducted to explore the structural performance of the columns. An experimental database of high-strength CFST stub columns consisting of 170 group test data was established, and the applicability of current design codes was assessed based on this database. The conclusions derived within the parameter scope of the current study are summarized as follows:

(1) Axially compressed HCFHSST stub columnsexperienced failure modes incorporating steel tubular buckling and concrete crushing. The experimental results demonstrated that the CFST columns fabricated using steels with $f_{\mathrm{y}}=838.00 \mathrm{MPa}$ and $889.87 \mathrm{MPa}$ exhibited more adequate residual mechanical behaviors than those with steels of $f_{\mathrm{y}}=566.90 \mathrm{MPa}$ and 780.75 $\mathrm{MPa}$.

(2) After the steel tube buckles, itcontinues to confine the concrete around the buckled positions, resulting in an increase in the longitudinal concrete stress in those regions. The steel tube-concrete contact stress primarily exists at the corner region, which concentrates $0.29 \mathrm{~L}$ or $0.38 \mathrm{~L}$ inthe middle of the column. Before the peak-load is reached or when the constraint factor is relatively small, the contact stress near the column end is relatively high.

(3) Based on the parametric results, the $f_{\mathrm{y}}$ value of $838.00 \mathrm{MPa}$ can be regarded as a separation point for the improvement in the concrete strength $\left(\triangle f_{\mathrm{c}}^{\prime}\right)$ generated by the confinement action. Moreover, to achieve effective confinement effects and $\triangle f_{\mathrm{c}}^{\prime}$, the steel ratio of the column is suggested to be less than $20 \%$.

(4) The formulas provided in Eurocode 4, AISC 360, and GB 50936 are overall conservative to predict the peak-loads of axially loaded CFST stub columns fabricated using high-strength materials. Eurocode 4 is more accurate (calculation/test $=0.99$ and $\mathrm{COV}=0.08$ ) on average but unconservative for columns with CSS-HSC. The AISC 360 equations can be safely utilized for predicting the peak-loads of axially loaded high-strength CFST stub columns with compact sections.

\section{Acknowledgments}

This work was supported by the Key Project of National Natural ScienceFoundation of China, China (51938009), National Natural Science Foundation of China, China (51878419), and Liaoning Climbing Scholar Support Program, China (2018-0101).

\section{References}

[1] Xiong M.X., Xiong D.X. and Liew J.Y.R., "Behaviour of steel tubular members infilled with ultra high strength concrete", Journal of Constructional Steel Research, 138, 168-183, 2017.

[2] Xiang P., Ge H.B. and Jia L.J., "Advancement and applications of Japanese high performance steel in structural engineering", Advanced Steel Construction, 12(3): 245-262, 2016.

[3] Eurocode 4, Design of Composite Steel and Concrete Structures-Part 1-1: General Rules and Rules for Buildings, European Committee for Standardization, Brussels, 2004.

[4] ANSI/AISC360-16, Specification for Structural Steel Buildings, American Institute of Steel Construction, U.S., Chicago, 2016.

[5] GB50936-2014, Technical Code for Concrete filled Steel Tubular Structures, Ministry of Housing and Urban-Rural Development of the People's Republic of China, China Architecture \& Building Press, Beijing, 2014 (in Chinese).

[6] Du Y.S., Chen Z.H. and Xiong M.X., "Experimental behavior and design method of rectangular concrete-filled tubular columns using Q460 high-strength steel", Construction and Building Materials, 125, 856-872, 2016.

[7] Khan M., Uy B., Tao Z. and Mashiri F., "Behaviour and design of short high-strength steel welded box and concrete-filled tube (CFT) sections", Engineering Structures. 147, 458-472, 2017.

[8] Xiong M.X., Xiong D.X. and Liew J.Y.R., "Axial performance of short concrete filled stee tubes with high-and ultra-high-strength materials", Engineering Structures, 136, 494-510, 2017.

[9] Thai S., Thai H.T., Uy B. and Ngo T., "Concrete-filled steel tubular columns: Test database, design and calibration", Journal of Constructional Steel Research, 157, 161-181, 2019.

[10] Yan Y.X., Xu L.H., Li B., Chi Y., Yu M., Zhou K.K. and Song Y., "Axial behavior of ultra-high performance concrete (UHPC) filled stocky steel tubes with square sections", Journal of Constructional Steel Research, 158, 417-428, 2019.

[11] Lee H.J., Park H.G. and Choi I.R., "Compression loading test for concrete-filled tubula columns with high-strength steel slender section", Journal of Constructional Steel Research, 159, 507-520, 2019.

[12] Lai Z.C. and Varma A.H., "High-strength rectangular CFT members: Database, modeling, and design of short columns", Journal of Structural Engineering, 144(5), 04018036, 2018.

[13] Lam D. and Williams C.A., "Experimental study on concrete filled square hollow sections", Steel and Composite Structures, 4(2), 95-112, 2004.

[14] Guler S., Çopur A. and Aydogan M., "A comparative study on square and circular high strength concrete-filled steel tube columns", Advanced Steel Construction, 10(2), 234-247, 2014.

[15] Aslani F., Uy B., Tao Z. and Mashiri F., "Behaviour and design of composite columns incorporating compact high-strength steel plates", Journal of Constructional Steel Research, $107,94-110,2015$

[16] Liang Q.Q. and Fragomeni S., "Nonlinear analysis of circular concrete-filled steel tubula short columns under axial loading", Journal of Constructional Steel Research, 65(12), 
2186-2196, 2009.

[17] Patel V.I., Hassanein M.F., Thai H.T., Al Abadi H., Elchalakani M. and Bai Y., "Ultra-high strength circular short CFST columns: Axisymmetric analysis, behaviour and design", Engineering Structures, 179, 268-283, 2019.

[18] Wei J.G., Luo X., Lai Z.C. and Varma A.H., "Experimental behavior and design of high-strengthcircular concrete-filled steel tube short columns", Journal of StructuralEngineering, 146(1): 04019184, 2020.

[19] Architectural Institute of Japan (AIJ). Recommendations for design and construction of concrete-filled steel tubular structures. Tokyo, 333, 1997.

[20] Kang W.H., Uy B., Tao Z. and Hicks S., "Design strength of concrete-filled steel columns", Advanced Steel Construction, 11(2), 165-184, 2015.

[21] AS 5100.6 - 2004, Bridge Design - Part 6: Steel and Composite Construction, Standards Australia, Sydney, 2004

[22] Lai B.L., Liew J.Y.R. and Xiong M.X, "Experimental and analytical investigation of composite columns made of high strength steel and high strength concrete", Steel and Composite Structures, 33(1), 67-79, 2019.

[23] Yang C., Yu Z.X., Sun Y.P., Zhao L. and Zhao H., "Axial residual capacity of circular concrete-filled steel tube stub columns considering local buckling", Advanced Steel Construction, 14(3), 496-513, 2018

[24] Ibañez C., Hernández-Figueirido D. and Piquer A., "Shape effect on axially loaded high strength CFST stub columns", Journal of Constructional Steel Research, 147, 247-256, 2018

[25] Zhou X.H., Gan D., Liu J.P. and Chen Y.F., "Composite effect of stub square steel tubed columns under axial compression", Advanced Steel Construction, 14(2), 274-290, 2018.

[26] Xu J.J., Chen Z.P., Xiao Y., Demartino C. and Wang J.H., "Recycled aggregate concrete in FRP-confined columns: a review of experimental results", Composite Structures, 174, 277-291, 2017.

[27] Wang H.Y. and Zha X.X., "Axial strength of CFST columns considering concrete age", Advanced Steel Construction, 10(2), 139-150, 2014.

[28] Wang Y.B. and Liew J.Y.R., "Constitutive model for confined ultra-high strength concrete in steel tube", Construction and Building Materials, 126, 812-822, 2016.

29] Zhang S.M., Guo L.H., Ye Z.L. and Wang Y.Y., "Behavior of steel tube and confined high strength concrete for concrete-filled RHS tubes", Advances in Structural Engineering, 8(2), $101-116,2005$

[30] Wang Q.W., Shi Q.X., Lui E.M. and Xu Z.D., "Axial compressive behavior of reactive powder concrete-filled circular steel tube stub columns", Journal of Constructional Steel Research, 153, 42-54, 2019.

[31] Li G.C., Chen B.W., Yang Z.J. and Feng Y.H., "Experimental and numerical behaviour of eccentrically loaded high strength concrete filled high strength square steel tube stub columns", Thin-Walled Structures. 127, 483-499, 2018.

[32] Tao Z., Wang Z.B. and Yu Q., "Finite element modelling of concrete-filled steel stub columns under axial compression”, Journal of Constructional Steel Research, 89, 121-131, 2013.

[33] Lin S.Q. and Zhao Y.G., "Numerical study of the behaviors of axially loaded large-diameter CFT stub columns", Journal of Constructional Steel Research, 160, 54-66, 2019.

[34] Han L.H., Yao G.H. and Tao Z., "Performance of concrete-filled thin-walled steel tubes under pure torsion", Thin-Walled Structures, 45(1), 24-36, 2007.

[35] ACI 363R-92 (1997), State-of-the-Art Report on High-Strength Concrete, ACI Committee 363 ; Detroit.

[36] Logan, A., Choi, W., Mirmiran, A., Rizkalla, S. and Zia, P., "Short-term mechanical properties of high-strength concrete", ACI Materials Journal, 106(5), 1-7, 2009.

[37] Li G.C., Yang Z.J. and Lang Y., "Experimental behavior of high strength concrete-filled square steel tube under bi-axial eccentric loading", Advanced Steel Construction, 6(4): 963-975, 2010.

[38] Yang Y.L., Wang Y.Y. and Fu F., "Effect of reinforcement stiffeners on square concrete-filled steel tubular columns subjected to axial compressive load", Thin-Walled Structures, 82, 132-144, 2014

[39] Sakino K., Nakahara H., Morino S. and Nishiyama I., "Behavior of centrally loaded concrete filled steel-tube short columns", Journal of Structural Engineering, 130(2), 180-188, 2004.

[40] Liu D.L. and Gho W.M., "Axial load behaviour of high-strength rectangular concrete-filled steel tubular stub columns", Thin-Walled Structures, 43(8), 1131-1142, 2005.

[41] Young B. and Ellobody E., "Experimental investigation of concrete-filled cold-formed high strength stainless steel tube columns", Journal of Constructional Steel Research, 62, 484-492, 2006.

[42] Yu Q., Tao Z. and Wu Y.X., "Experimental behaviour of high performance concrete-filled steel tubular columns", Thin-Walled Structures, 46, 362-370, 2008.

[43] Cederwall K., Engstrom B. and Grauers M., "High-strength concrete used in composite columns", Special Publication, 121, 195-214, 1990.

[44] Han L.H., Yao G.H. and Zhao X.L., "Tests and calculations for hollow structural steel (HSS) stub columns filled with self-consolidating concrete (SCC)", Journal of Constructional Steel Research, 61, 1241-1269, 2005.

[45] Uy B., "Strength of short concrete filled high strength steel box columns", Journal of Constructional Steel Research, 57(2), 113-134, 2001

[46] Du Y.S., Chen Z.H. and Yu Y.J., "Behavior of rectangular concrete-filled high-strength steel tubular columns with different aspect ratio", Thin-Walled Structures, 109, 304-318, 2016.

[47] Liu D.L., "Tests on high-strength rectangular concrete-filled steel hollow section stub columns", Journal of Constructional Steel Research, 61(7), 902-911, 2005.

[48] Liu D.L., Gho W.M. and Yuan J., "Ultimate capacity of high-strength rectangular concrete-filled steel hollow section stub columns", Journal of Constructional Steel Research, 59(12), 1499-1515, 2003. 